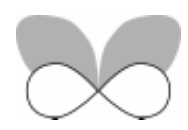

\title{
Towards a hierarchical framework for modelling the spatial distribution of animals
}

Brendan G. Mackey ${ }^{1}$ and David B. Lindenmayer ${ }^{2}{ }^{1}$ School of Resources, Environment and Society, The Australian National University, Canberra, ACT 0200, Australia and ${ }^{2}$ Centre for Resource and Environmental Studies, The Australian National University, Canberra, ACT 0200, Australia

\begin{abstract}
Aim A hierarchical framework is presented for modelling the spatial distribution of terrestrial vertebrate animals.

Location The location of the study is the montane ash forests of the Central Highlands of Victoria, south-eastern Australia.

Methods The framework is illustrated using as a case study the distribution of Leadbeater's Possum [Gymnobelideus leadbeateri McCoy, 1867, (Marsupialia: Petauridae)], a small arboreal marsupial. The framework is based upon quantifying the environmental response of a species in terms of a five-level environmental hierarchy defined by scales (global-, meso-, topo-, micro- and nano-scales) that represent natural breaks in the distribution and availability of the primary environmental resources. Animal response is examined in terms of a species' distribution as observed in four biological units (the species in toto, meta-population/population, group/colony, and individual organism). We define the spatial occurrence and abundance of the target species in each of these units as its 'distributional behaviour'.
\end{abstract}

Results Predictions of the potential spatial distribution of Leadbeater's Possum are presented at meso-, topo-, micro- and nano-scales. These spatial predictions utilize Geographical Information System (GIS)-based spatial models of long term mean monthly climate and terrain-modified surface radiation, together with vegetation cover and individual tree attributes from air-photo interpretation and field survey.

Main conclusions Ideally, species' responses at each level in the environmental hierarchy should be empirically derived using statistical models based on field observation of a species' distribution and abundance. Spatial modelling of species' responses becomes problematic at finer scales because of the lack of suitable environmental data. The key characteristics of the modelling framework are generic, but the influence of additional scales and processes will be important in other ecosystems and species.

\section{Keywords}

Spatial distribution, spatial modelling, terrestrial vertebrates, environmental hierarchy spatial scale, potential distributions, Leadbeater's Possum, south-eastern Australia.

\section{INTRODUCTION}

This paper presents an analytical framework for modelling the spatial distribution of animals. While the modelling framework has been developed in the context of forest

* Correspondence: Brendan G. Mackey, School of Resources, Environment and Society, The Australian National University, Canberra, ACT 0200, Australia, E-mail: brendan.mackey@anu.edu.au dependent vertebrate fauna, we argue this also provides the basis of a generic approach to modelling animal distributions in terrestrial ecosystems. Our paper is presented in four sections. First, we briefly review existing modelling frameworks. Secondly, we outline our new framework. Thirdly, this methodology is then explored using as a case study the distribution of Leadbeater's Possum [Gymnobelideus leadbeateri McCoy, 1867, (Marsupialia: Petauridae)]; a small Australian arboreal marsupial species. Finally, 
limitations of the methodology are discussed, including consideration of the extent to which the framework can be considered generic.

The distribution patterns of species are rarely uniform and continuous in space and time (Caughley, 1978), and the identification of factors that influence this variation is a fundamental question in ecology (e.g. Elton, 1927; Krebs, 1978; Brown, 1984; Nix \& Gillison, 1985). A wide range of factors influence the distribution of plants and animals and many of these operate at different spatial and temporal scales. They include abiotic processes, biologically mediated processes, and processes dominated by biotic interactions.

Various factors can be identified which complicate the study of terrestrial vertebrate distribution patterns. First, the unit of analysis can be an individual organism, a pair, a group or colony of animals, a population, a meta-population, or a species in toto - all may be needed to develop an adequate understanding of an animal's distribution. Secondly, terrestrial vertebrates are mobile and, as a result, there is an inherent degree of stochasticity in their distribution patterns. This means that some places which appear to support suitable conditions remain unoccupied (Van Horne, 1983; Hanski, 1994). Thirdly, the environmental conditions that impinge upon animal function and provide the resources directly utilized by an animal, are not uniformly distributed in space and time. Thus, the variation in the distribution and abundance of these primary environmental resources will directly and indirectly effect the distribution of animals. Fourthly, the distribution of a given species may be influenced by the activities of other animals such as predators, competitors, parasites as well as inherent population pulses such as die-offs (Krebs, 1978).

The concepts of habitat and niche are central to the problem of animal distributions. These concepts refer to the relationships between a species and the impinging environment (that is, the effective environment it experiences). Depending on the definitions adopted, these concepts can be variably defined in terms of the taxon's potential physiological response, the environmental conditions actually occupied by the taxon, constraining physical environmental conditions external to the biotic community, the taxon's shelter and nutrient requirements, or site-level biotic interactions (see Discussion in Davey \& Stockwell, 1991).

Given the complexity of factors that potentially impinge on patterns of animal distribution, it could be argued that a general methodology for modelling the spatial distribution of animals cannot be developed and a taxon-specific approach is required. However, many authors have rejected this view, and have proposed various frameworks for investigating animal distributions. These frameworks reflect widespread recognition of the need to study ecological phenomena from a multi-scaled perspective, both generally (Gillier \& Gee, 1987; Meentemeyer \& Box, 1987; Wiens et al., 1987; Turner et al., 1989; Wiens, 1989; Allen \& Hoekstra, 1992; Schneider, 1994; Jaquet, 1996) and in respect of specific taxa, including plants (Forman, 1964; Jarvis \& McNaughton, 1986; Carter \& Prince, 1988) and invertebrates (Gutzwiller \& Anderson,
1987; Roughgarden et al., 1987). Similarly observations have been made in respect of physical environmental phenomena such as meteorology (Orlanski, 1975; Linacre, 1992), hydrology (Strahler, 1957), geophysics (Pedlosky, 1979) and oceanography (Stommel, 1963). They also reflect the need to examine phenomena inclusive of spatially distributed (landscape-wide) patterns and processes and the role of environmental constraints and resource availability (Christian \& Stewart, 1953; Troll, 1972; Forman \& Godron, 1986; Milne et al., 1992; Wiens et al., 1993; Forman, 1995).

Urban et al. (1987) conceptualized forest landscapes as a hierarchy of nested spatial units: physiographic provinces (10,000 ha); watersheds/local drainage basins (100 s$1000 \mathrm{~s} \mathrm{ha}$ ); stands (at the scale of topographic position, or because of disturbance, $1 \mathrm{~s}-10 \mathrm{~s}$ ha); and gaps (reflecting the influence of single big trees, 0.01-0.1 ha). Each level can be characterized by differently scaled disturbances, forest processes, environmental constraints, and vegetation patterns, with subsequent consequences for animal distributions. Poff (1997) proposed a model for use in stream ecology based on matching species traits to a hierarchy of four 'habitat filters', namely: watershed/basin filters; valley/reach filters; channel unit filters; and microhabitat filters. Each level or filter was characterized by constraining landscape features.

Davey \& Stockwell (1991) proposed that wildlife habitat is best understood and modelled by considering a hierarchy of constraining influences at five levels: climatic envelope; nutrient envelope; vegetation structure; shelter, nesting resources; and interspecific interactions. Within each level, a host of processes, interactions, and flows occur that provide the basis for deriving empirical habitat relationships.

Holling (1992) developed an analytical framework based on the notion that the landscape is hierarchically structured by a small set of structuring processes into a limited number of nested levels. Each level has its own physical textures and temporal frequencies, with higher levels entraining lower level phenomena. In a forest context, Holling (1992) suggested that at least six hierarchical levels can be identified, each of which is dominated by one category of structuring process, namely: needle; crown; patch/gap; tree stand; and landscape zone. He further argued that animals demonstrate a hierarchy of decisions, increasing in scale from food to foraging area to home range area, and that the structuring processes and behavioural decisions by the animal intersect, producing scale-dependent biotic responses, in particular, spatial scaling of body mass.

Some commonality emerges from this brief overview of published frameworks. First, all the authors cited above recognized that both species' response (particularly behavioural response as it relates to distributions) and impinging abiotic and/or biotic environmental conditions are hierarchically scaled in space and time. Secondly, the various environmental levels identified by these authors represent attempts to identify scales which are critical in the distribution and availability of primary resources, in particular, those that define optimum/permissible physiological conditions, and food and shelter resources. 


\section{PROPOSED FRAMEWORK}

In this paper, we build upon the foundation concepts outlined above by first refining Holling's (1992) hierarchy of scaled structuring processes. As our organizing principle, we use the scale-dependent delivery of the primary environmental resources that control biological productivity (Nix \& Gillison, 1985; Mackey et al., 1988; Mackey, 1996). These primary environmental resources are heat, light, water and mineral nutrients. They directly influence both animal physiology and the productivity and structure of vegetation upon which animals depend for shelter and nutrients.

We identify a five-level hierarchy of scales. This hierarchy shows similarities with those proposed by the authors cited above. However, our levels differ in that they are selected principally in terms of spatial scales which represent natural breaks in the distribution and availability of the primary environmental resources. Therefore, these levels are not arbitrary as they represent critical scales where there is a major change in the dominant processes controlling the distribution and availability of the primary environmental resources. The five levels also reflect a further logistic constraint, namely, that the dominant processes are amenable to spatial analysis by Geographical Information System (GIS)-based environmental modelling or remote sensing (Burroughs, 1986) (this is because we are interested in generating landscape-wide predictions of animal distribution patterns in real landscapes).

The third key characteristic of our framework concerns the biological unit of analysis. Our analyses are based on animal distributions as observed in four biological units, namely: the individual organism; a group or colony of animals; a meta-population or population; and the species distribution in toto. We refer to the spatial occurrence and abundance of the target taxa in each of these units as its 'distributional behaviour'. Whereas Holling (1992) referred to a hierarchy of decisions, we identify a hierarchy of individual and collective animal distributional behaviours.

A fourth critical characteristic concerns the manner in which species-environment relationships are defined. In line with Davey \& Stockwell (1991), we argue that animal responses must be empirically derived by using statistical relationships that correlate field observations of the animal's distributions with key environmental attributes. Thus, our general framework is underpinned by quantitative, locationspecific statistical relationships.

The fifth distinguishing characteristic is that we utilize quantitative spatial models of the primary environmental resources rather than surrogates based on landscape features obvious to human observers. Thus, the space/time distribution of the primary environmental resources is explicitly and precisely defined - at least to the extent allowed by available data and technology. These spatially distributed models of the primary environmental resources provide the basis for generating landscape-wide predictions of a species' distributional behaviour (as defined above).

The focus on primary environmental resources establishes the conceptual and physical basis for integrating an animal's responses through the five levels of our environmental hierarchy. Each level contains approximations of the distribution and availability of heat, light, water and mineral nutrients; although these are the result of differing physical and biological processes at each level. Consequently, the predictions of the distribution of an animal generated by the empirical relationships are spatially nested.

The following sections provide a more detailed account of our modelling framework.

\section{The delivery of primary environmental resources}

The primary environmental resources of light, heat, water and mineral nutrients exert fundamental controls on biological processes because they: (1) influence the rate of biochemical reactions; (2) comprise the basic resources needed to sustain physiological functions and (3) provide the raw materials for biological growth. Hence, they provide the general environmental context within which organisms persist and constitute a basic set of constraints with which an organism must contend (see Forman, 1964; Fitzpatrick \& Nix, 1970; Nix \& Kalma, 1972; Nix et al., 1977; Nix, 1986; Woodward \& Williams, 1987; Mackey et al., 1988; Austin et al., 1990; Nix \& Switzer, 1991; Prentice et al., 1992; Mackey, 1993, 1994; Lindenmayer et al., 1996). Thus, information about the distribution of the primary environmental resources is crucial to understanding an animal's distribution.

The totality of biophysical processes that determine the distribution and availability of the primary environmental resources operate across a continuum of scales. However, the processes that dominate the delivery of the primary environmental resources relevant to the distribution of animals are scale-specific. Here, we classify them into five levels, ordered hierarchically from large to small: global-, meso-, topo-, micro- and nano-scales.

At the global-scale, the main process influencing the space/ time distribution of the primary environmental resources is latitudinal and seasonal variation in extra-terrestrial radiation - the main driver of global weather and climate (Lowry, 1967; Linacre, 1992). At the meso-scale, two main processes can be identified. First, the interactions between the prevailing weather systems and (in particular but not limited to) topographic elevation which, via lapse rate effects, controls long-term precipitation and the thermal and radiation conditions experienced by a landscape (Sellers, 1991; Linacre, 1992). These climatic conditions are the main sources of water and energy into a landscape. Meso-scaled climate is therefore different from global-scaled climate in that it represents spatially and temporally finer variation in the delivery of water and energy as influenced by, inter alia, broad-scale topographic features.

Secondly, the lithology of the geological substrate exerts a major control on the nutrient status of the regolith and soil profile (Webb, 1968; Swanson et al., 1988). Spatial variability at the meso-scale in soil parent material is therefore often associated with different vegetation structures, life forms and plant physiognomy (Mackey, 1993, 1994). 
This reflects the influence of nutrient availability on plant productivity. However, soil parent material can vary substantially at topo-scales in certain landscapes such as boreal forest ecosystems (Mackey et al., 1996). Also, air-borne soil particles associated with precipitation may contribute significant quantities of mineral nutrients to a landscape (see Walker et al., 1981; Golley, 1983). Rock types also affect the way in which landscapes erode, and hence how landform patterns evolve. Meso-scaled climatic factors also affect nutrient availability because the moisture and thermal regimes influence the rate of bedrock weathering and soil water $\mathrm{pH}$ (Swanson et al., 1988; Briggs \& Smithson, 1992).

At the topo-scale, the local topography modifies the mesoscaled inputs of precipitation, temperature, radiation, potential evaporation and nutrients (Ostendorf, 1966; Mackey et al., 1988; Moore et al., 1993). Terrain attributes such as slope angle, slope length, and up-slope contributing area, determine the extent to which any given location sheds or receives water (Moore et al., 1993; Mackey et al., 1996). Catchment hydrological processes that determine run-on and run-off can also influence where plant nutrients accumulate in a landscape, given that mineral nutrients must be in solution to be taken up by plants (Taiz \& Zeiger, 1991; Briggs \& Smithson, 1992).

Micro-scale in a forest context refers to the impact of the forest canopy on below-canopy conditions including the soil water balance, although the nature of the canopy's influence on the water regime varies between ecosystems (Miller, 1978). Lower radiation levels due to a dense canopy can reduce incoming solar radiation and hence soil evaporation, thereby improving the water balance (Rosenberg et al., 1983). Conversely, young dense stands can increase total evaporation as a result of their larger leaf area index (Grayson et al., 1992). At a micro-scale therefore, vegetation canopy cover exerts a strong influence on the light, heat, water and mineral-nutrient conditions experienced by subcanopy plants and animals. The vegetation structure at the micro-scale is also a major store of nutrients which represents a buffer against losses of nutrients caused by soil erosion and leaching.

Nano-scale processes refer to below-canopy scaled processes. These include: (1) the resource heterogeneity represented by the vertical layering of the vegetation, (2) variation in the amount and kind (dead/living) of woody biomass (Harmon et al., 1986), and (3) the role of soil microorganisms (e.g. bacteria, fungi and algae) in nutrient cycling processes such as nitrification, mineralization and de-nitrification (e.g. Attiwill \& Leeper, 1987). Also, competition between plants influences the nano-scale distribution of water and nutrients in the soil profile through the preemption of resources by competitively superior individuals (Harper, 1977) (also see ecological field theory, Walker et al., 1986).

Micro- and nano-scaled processes represent smaller-scaled controls on the primary environmental resources by the biota itself. These can create levels of available resources that are substantially different from those generated by meso- and topo-scaled process. The larger scaled-processes therefore constrain (rather than strictly contain) the microand nano-scaled delivery of the primary environmental resources in all circumstances. Indeed, the forest canopy can influence meso-scaled regional precipitation resources (Eltahir \& Bras, 1994). Even the global biogeochemical cycles (such as the carbon cycle) are strongly modulated by the large scale integration of the locally scaled, biotically driven process of plant photosynthesis and respiration (Gorshkov, 1995). However, here we choose to assume that the delivery of the primary environmental resources is predominately a spatially nested phenomena.

The suite of global- to nano-scaled biophysical processes define an animal's effective environment; that is, the set of prevailing environmental conditions that impinge upon, or are available to, an animal. This is similar to other schemas for modelling the environmental constraints on plants such as Franklin (1995). However, our framework shares with that proposed by Holling (1992), an explicit recognition that the distribution and availability of the primary environmental resources involves both larger scaled abiotic physical inputs and smaller scaled biotically driven processes.

\section{Species distributional behaviour}

Spatial and temporal patterns of movement relate to an animal's need to seek food, shelter, reproduce, minimize competition and avoid predation. These behaviours geographically connect an animal to the environment. This is because they motivate an animal to move through a landscape to seek particular resources. As prevailing 'effective' environmental conditions act to promote or constrain an animal's behaviour, it follows that the hierarchically scaled, landscape-wide patterns of availability in the primary environmental resources will influence (and hence potentially correlate with) the spatial distribution of the animal.

Like the multi-scaled physical processes discussed above, patterns in a species' distributional behaviour can be examined as levels in a hierarchy. Hence, we can consider the distributional patterns of: (1) a species in toto, (2) a population or meta-population, (3) a pair, group or colony and (4) an individual organism. For a given taxon, each of these biological units will tend to equate with a corresponding level (or levels) in the environmental hierarchy. For example, patterns of distribution associated with the species in toto may reach equilibrium over the course of decades or centuries with global- and meso-scaled environmental processes associated with climate; population level patterns of distributions might show considerable year-to-year variation in conditions operating at extents and frequencies consistent with the topo-scales; a colony will be more responsive to processes operating at the micro-scale; while individual organisms' patterns of movement can vary through the course of the day in response to nano- (i.e. below canopy) scaled affects.

There will not always be a consistent, one-to-one correspondence between levels in the biological and environmental hierarchies. Certainly when comparing species, as noted by Allen \& Hoekstra (1992), the spatial extent of a single 
organism can be greater than that spanned by all populations of another species. Within a species, the dispersal of an individual or group at particular periods in an organism's life cycle may exceed the usual spatial extent of a population. The actual scale (spatial extent and grain, and frequency of movement) of distribution for a given biological unit will depend on the mobility of the animal targeted for study.

In summary, we suggest that there are two fundamental hierarchies whose intersection must be explicitly considered when modelling the spatial distribution of an animal. These are: (1) the nested hierarchy of abiotic and biotic processes that determine the distribution and availability of the primary environmental resources (the environmental hierarchy), and (2) the often nested (but sometimes non-nested) hierarchy of patterns of distributional behaviour associated with the set of biological units (the behavioural hierarchy).

Ecological studies are usually focused on one of the levels in the behavioural hierarchy (e.g. they select distributional behaviours associated with an individual organism or a meta-population) and one or two levels in the environmental hierarchy that seem to be similarly scaled. We suggest that a substantial model of an animal's distribution can only be generated by considering the intersection of all levels of both hierarchies.

\section{Modelling a species potential distribution}

While generalized large scale (i.e. small scale in a conventional cartographic sense) maps of species distributions, such as traditionally represented in wildlife atlases (e.g. Blakers et al., 1984; Saunders \& Ingram, 1995), are often a useful starting point for examining the distribution patterns of an organism, they provide little information about causal factors underpinning why an animal occurs where it does. Furthermore, a coarse outline of the geographical limits of a species' distribution does not provide information on the impact of distributional behaviour associated with a metapopulation, or of smaller scaled processes associated with the selection of a shelter site by an individual.

An area of potentially suitable environment within broad distribution limits may not be occupied because of factors such as past disturbance, impaired dispersal capability, or random effects. Therefore, the only way of knowing if an animal is present at a location is to actually observe it in situ. However, such an observation does not provide information on whether the animal will be present at other unsampled locations, or at the same location at another point in time. In addition, it is impossible to comprehensively survey all locations on a repeated long-term basis (Margules \& Stein, 1989). Moreover, the cost of collecting such data would be prohibitive. Even if were logistically and financially feasible to collect these data, the value of such location information might date quickly as the condition of an area changes and becomes unsuitable (e.g. if a patch of forest is burnt and no longer supports the key food plants needed by a particular species) (Burgman \& Lindenmayer, 1998). There may be special circumstances where it is feasible to track the movement of all members of a species throughout their life cycles, and hence, at a given point in time, generate a map of the species distribution and abundance. However, we argue that a more realistic aim is to use survey data to predict the probability of the occurrence of a species.

We argue that predictions of an animal's distribution, at a specified level in the behavioural hierarchy, must be derived from empirical functions based on statistical analyses of relationships between: (1) the occurrence of the target taxon made from field observations and (2) a candidate set of explanatory variables that quantify the distribution and availability of the primary environmental resources at a given level in the environmental hierarchy. Once such a statistical function has been calculated, and given that spatial estimates of the explanatory variables are available for the target landscape, a prediction of the potential spatial distribution of the animal can be generated. Measures of uncertainty in the statistical relationship, such as confidence intervals, can then be used to indicate the degree of likely error in the spatial prediction (e.g. Lindenmayer et al., 1995). As predictions of the broad distribution limits of a species will not necessarily provide appropriate information at other scales, predictions are required for each level in the behavioural hierarchy taking account of the influences of each level in the environmental hierarchy.

Notably, the use of a statistical function based on relationships between a response (independent) variable and a set of explanatory (dependent) variables is a fundamentally different approach from methods such as Habitat Suitability Indices (HSI) (reviewed by Van Horne \& Wiens, 1991). The HSI models are typically simple descriptive constructs based on human perceptions of the structural complexity or number of strata in the vegetation (e.g. Short, 1984) considered to be critical components of the habitat of a species (e.g. Laymon et al., 1985). Suitability indices for these factors are assigned relative weightings and a range of different mathematical operations can then be used to integrate them to a give an overall value for the HSI. While considerable effort has been directed toward constructing HSI models, the more difficult and costly process of testing and validating them has largely been neglected (Block \& Brennan, 1993). The lack of validation has been a major criticism of the use of the technique (Burgman \& Lindenmayer, 1998). Nonetheless, HSI models can provide a useful synthesis of published habitat relations as a preliminary step in implementation of our methodology.

One of the keys to predicting animal distribution lies in the ability to develop spatially distributed estimates of the primary environmental resources on a landscape-wide basis. This requires that various environmental models be integrated within a Geographical Information System (GIS), to generate the necessary spatial data. We re-iterate that the outcome will not be a map of distributions, but rather a probability of occurrence for a specified level in the behavioural hierarchy as a function of processes operating at a given level or levels in the environmental hierarchy.

Recent developments in computer-based tools for geographical and environmental analyses have transformed the 
ability to generate reliable spatial estimates of the distribution of heat, light, water and nutrients, particularly at meso-, topo- and micro-scales. Improved techniques are now available to model long-term mean monthly climate at the meso-scale (Nix, 1986; Hutchinson, 1991, 1995) (also see Price et al., 2000 for a comparison of widely used climate interpolation procedures).

Similarly, methods are now available to model the topographic controls on radiation and catchment hydrology. For example, the TAPES library of computer programs (see Moore et al., 1993) provide the capacity to predict soil water indices and surface radiation based on terrain analysis using appropriately scaled digital elevation models. Such methods have been applied in a range of landscapes (Gallant \& Wilson, 1996; Wilson, 1996; Wilson \& Gallant, 1996, 2000; McKenney et al., 1999; Mackey et al., 2000). Spatially distributed values of vegetation canopy structure can be generated from remotely sensed sources, thereby providing data about micro-scale processes (e.g. Harrison \& Jupp, 1990). Details of some of these methods are provided in the case study outlined below. The integration and application of these environmental models is a key component of our proposed modelling framework.

\section{CASE STUDY: THE SPATIAL DISTRIBUTION OF LEADBEATER'S POSSUM}

We illustrate our hierarchical modelling framework using the distribution of Leadbeater's Possum (Gymnobelideus leadbeateri) in south-eastern Australia, as a case study. This application is based on a brief synthesis of published investigations of the species that have been completed based on field data recorded at different spatial grains of observation (Table 1). The results of some new topo-scaled analyses are also presented.

Leadbeater's Possum is a small (110-160 g), cryptic species of nocturnal arboreal marsupial. The broad-scale distribution limits of the species are confined to a region c. $60 \mathrm{~km} \times 80 \mathrm{~km}$ in area known as the Central Highlands of Victoria, located c. $100 \mathrm{~km}$ north-east of the city of Melbourne (Lindenmayer et al., 1991a; Fig. 1). Leadbeater's Possum is virtually confined to montane ash forests comprised of either Mountain Ash (Eucalyptus regnans F. Muell), Alpine Ash (Eucalyptus delegatensis R. Baker) or Shining Gum (Eucalyptus nitens Maiden) (Lindenmayer et al., 1989).

Leadbeater's Possum lives in groups or colonies of 3-12 individuals (Smith, 1984a). Animals make a nest in a hollow within a large mature tree, and spend $c .75 \%$ of their time inside such cavities (Smith et al., 1982). The species consumes a variety of food resources, including arthropods, honeydew (which is a sugar-rich secretion produced by phloem-feeding, lerp-forming insects) and plant exudates especially saps produced by understorey Acacia spp. trees (Acacia dealbata Link, A. obliquinervia Tindale, and A. frigescens J.H. Willis) (Smith, 1984b; Lindenmayer et al., 1994a).

\section{Defining the environment responses of Leadbeater's Possum}

Global- and meso-scales

At the global- and meso-scales, the target behaviour is the species' distribution in toto; that is, all populations of Leadbeater's Possum. Fossil evidence indicates that the distribution of the species has expanded and contracted in south-eastern Australia during the past 5000-100,000 years in response to repeated changes in climatic conditions such as the Pleistocene glacial and Holocene pluvial periods (Lindenmayer, 1996). Similarly, such climatic changes have strongly influenced long-term temporal variations in the distribution ranges of the forests on which Leadbeater's Possum depends (Kershaw, 1981; Hope, 1984) including understorey Acacia spp. trees (Pedley, 1986).

The known extant distribution of Leadbeater's Possum was examined using the BIOCLIM modelling system (see Nix, 1986) that explored the climatic determinants of the distribution patterns of the species (Lindenmayer et al., 1991a; see below). As discussed below, even within apparently suitable areas of meso-scaled climatic conditions, the spatial distribution of Leadbeater's Possum is not continuous and uniform. This emphasizes the importance of examining factors operating at lower levels in the environmental hierarchy.

\section{Topo-scale}

At the topo-scale, the key animal distributional behaviours are those that relate to the distribution of, and interactions between, populations of Leadbeater's Possum. Factors like dispersal mechanisms, dispersal capability, and metapopulation dynamics appear to be important at this scale. A range of field-based and computer-simulation studies have revealed that the amount, shape and spatial configuration of suitable vegetation patches are important factors influencing the distribution of Leadbeater's Possum within areas of montane ash. These studies have indicated that: (1) small, isolated patches of suitable vegetation have a low probability of being occupied by Leadbeater's Possum (Lindenmayer \& Lacy, 1995; Lindenmayer \& Possingham, 1995a), and (2) the shape of areas of suitable vegetation is an important factor controlling the spatial distribution of Leadbeater's Possum - the species is typically absent from narrow strips of forest retained within logged montane ash landscapes (Lindenmayer \& Nix, 1993) although the structure of the forest in the strips was predicted to be potentially suitable for Leadbeater's Possum (based on validated models of the forest structure required by the animal - see below) (Lindenmayer et al., 1993a).

Within the constraints set by meso-scaled processes, toposcaled environmental conditions will have an important effect on site productivity, the fire regime and the development of stand conditions. Hence, they influence the suitability of vegetation for an organism. Water availability and soil moisture content may significantly influence the structure and quantity of the understorey vegetation in Australian forests (Specht, 1983; Specht \& Morgan, 1983). In the case 
Table I A summary of studies completed on the biology and ecology of Leadbeater's Possum and used to underpin the case study illustrating the operational framework for understanding distribution patterns of organisms

\begin{tabular}{|c|c|c|c|}
\hline Investigation & Data sets/type of study & Spatial grain of field observation & Reference/s \\
\hline Biogeography & Fossil records & $\begin{array}{l}\text { Records over } 1000 \mathrm{~s} \mathrm{~km}^{2} \\
\text { (eastern Australia) }\end{array}$ & Lindenmayer (1989, (1996) \\
\hline $\begin{array}{l}\text { Animal bioclimatic } \\
\text { relationships }\end{array}$ & 165 Distribution records & $60 \mathrm{~km} \times 80 \mathrm{~km}$ area & Lindenmayer et al. (1991a) \\
\hline Habitat requirements & $\begin{array}{l}207 \text { Sites, } 30 \text { vegetation } \\
\text { measures, } 1638 \text { plots }\end{array}$ & $\begin{array}{l}200 \mathrm{~m} \times 150 \mathrm{~m} \text { (survey site) } \\
10 \mathrm{~m} \times 10 \mathrm{~m}(\text { plot })\end{array}$ & Lindenmayer et al. (1991b, 1994a) \\
\hline Nest tree requirements & 1829 Trees, 10 tree measures & $5 \mathrm{~m} \times 2 \mathrm{~m}($ tree $)$ & $\begin{array}{l}\text { Lindenmayer et al. (1990c, 1991c, } \\
\text { 1994b) }\end{array}$ \\
\hline Spatial distribution of habitat & 520 Sites, 3120 plots & $\begin{array}{l}200 \mathrm{~m} \times 150 \mathrm{~m} \text { (survey site) } \\
10 \mathrm{~m} \times 10 \mathrm{~m}(\text { plot })\end{array}$ & $\begin{array}{l}\text { Lindenmayer et al. (1991e), } \\
\text { Lindenmayer \& Cunningham (1996) }\end{array}$ \\
\hline $\begin{array}{l}\text { Temporal changes in } \\
\text { habitat suitability }\end{array}$ & 181 Sites, 1737 trees & $\begin{array}{l}200 \mathrm{~m} \times 150 \mathrm{~m} \text { (survey site) } \\
5 \mathrm{~m} \times 2 \mathrm{~m} \text { (tree) }\end{array}$ & Lindenmayer et al. (1990a, 1997b) \\
\hline Use of wildlife corridors & $\begin{array}{l}\text { Forty-nine wildlife corridors, } \\
30 \text { measures, } 294 \text { plots }\end{array}$ & $\begin{array}{l}40-160 \mathrm{~m} \times 0.5-4 \mathrm{~km} \text { (corridor) } \\
10 \mathrm{~m} \times 10 \mathrm{~m} \text { (plot measures) }\end{array}$ & $\begin{array}{l}\text { Lindenmayer et al. (1993a), } \\
\text { Lindenmayer \& Nix (1993) }\end{array}$ \\
\hline Nest tree use & $\begin{array}{l}\text { One site, trap-recapture, } \\
\text { radio-tracking, } \\
\text { field observation }\end{array}$ & 30 ha (study site) & $\begin{array}{l}\text { Smith (1980, 1984a), } \\
\text { Smith et al. (1982), } \\
\text { Lindenmayer (1991), } \\
\text { Lindenmayer \& Meggs (1996), } \\
\text { Lindenmayer et al. (1991d), } \\
\text { Lindenmayer (1996) }\end{array}$ \\
\hline Meta-population dynamics & $\begin{array}{l}\text { Simulation models that } \\
\text { integrate biological data } \\
\text { and spatial data }\end{array}$ & $\begin{array}{l}0.5-500 \text { ha (patch) } \\
3000-7000 \text { ha (landscape) }\end{array}$ & $\begin{array}{l}\text { Lindenmayer \& Lacy (1995), } \\
\text { Lindenmayer \& Possingham (1995a) }\end{array}$ \\
\hline Parasitology & $\begin{array}{l}\text { Parasite collection from } \\
\text { trapped animals }\end{array}$ & $200 \times 150 \mathrm{~m}$ (survey sites) & Lindenmayer et al. (1994c) \\
\hline Disease & $\begin{array}{l}\text { Diagnoses of deaths of } \\
\text { captive animals }\end{array}$ & NA & Booth (1994) \\
\hline Diet & $\begin{array}{l}\text { Scat collection, surveys of prey } \\
\text { items and food resources }\end{array}$ & 30 ha (study site) & $\begin{array}{l}\text { Smith (1980, 1984b), } \\
\text { Lindenmayer et al. (1994a) }\end{array}$ \\
\hline $\begin{array}{l}\text { Social behaviour and life } \\
\text { history }\end{array}$ & $\begin{array}{l}\text { Trap-recapture and } \\
\text { radio-telemetry }\end{array}$ & 30 ha (study site) & $\begin{array}{l}\text { Smith (1980, 1984b), } \\
\text { Lindenmayer (1996), } \\
\text { Lindenmayer \& Meggs (1996) }\end{array}$ \\
\hline Energetics and metabolism & Tritiated water experiments & 30 ha (study site) & Smith et al. (1982) \\
\hline Distribution & Field surveys & $\begin{array}{l}200 \mathrm{~m} \times 150 \mathrm{~m} \text { (survey sites) } \\
60 \mathrm{~km} \times 80 \mathrm{~km} \text { area }\end{array}$ & $\begin{array}{l}\text { Seebeck et al. (1983), } \\
\text { Smith et al. (1985, 1989), } \\
\text { Lindenmayer et al. (1989), } \\
\text { Macfarlane (1988) }\end{array}$ \\
\hline Plant bioclimatic relationships & $\begin{array}{l}>2000 \text { Distribution records of } \\
10 \text { forest trees }\end{array}$ & $\begin{array}{l}\text { Records over } 1000 \mathrm{~s} \mathrm{~km}^{2} \\
\text { (eastern Australia) }\end{array}$ & $\begin{array}{l}\text { Lindenmayer et al. (1991a) } \\
\text { Lindenmayer (1996) }\end{array}$ \\
\hline
\end{tabular}

of montane ash forests, this could influence the development of stands of understorey Acacia spp. which are, in turn, an important food resource for Leadbeater's Possum (Lindenmayer et al., 1994a). The thermal regime experienced within tree hollows will vary between sites in response to differences in ambient conditions; that is, as constrained by the meso- and topo-scaled air temperatures (Calder et al., 1983). Extremes of temperature can be an important factor influencing hollow selection by arboreal marsupials (Calder et al., 1983; Lindenmayer et al., 1990b) and they may be critical for a small, highly energetic species such as Leadbeater's Possum for which the conservation of energy during the time spent in the nest is important (Smith et al., 1982). Other likely effects include the influence of topo-scale thermal and moisture resources on the rate of flow of gum exudates eaten by Leadbeater's Possum (Hansford, 1985), and the rate of cavity decay and ontogeny in trees (Lindenmayer et al., 1997) which may, in turn, effect the development of suitable nest sites for Leadbeater's Possum (Lindenmayer et al., 1993b).

Terrain attributes have also been shown to directly and indirectly influence the distribution of Leadbeater's Possum populations on a landscape-wide basis. The species was found to be less likely on steep slopes (Lindenmayer et al., $1991 b, 1994 b$ ) and this can be attributed to a number of interrelated factors including the reduced likelihood of hollow bearing trees on these slopes (Lindenmayer et al., 1991e), and energy conserving behaviour by small-sized mammal. Analyses by Lindenmayer et al. (1999) have also shown that potentially suitable habitat patches within 


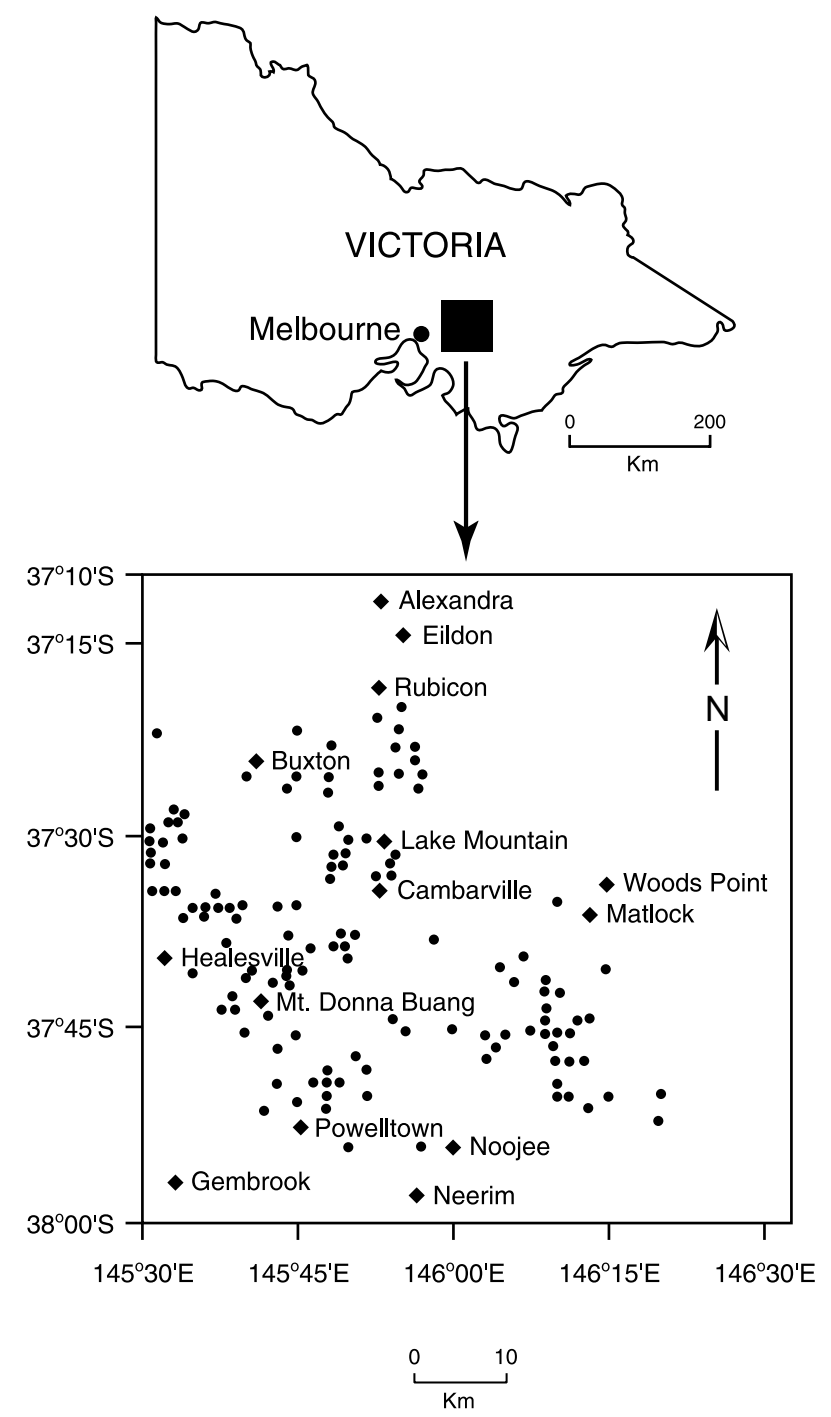

Figure I Location of the Central Highlands of Victoria shown as a black square in the top map. The subdiagram shows the major towns in the Central Highlands region (diamonds) and the point locations of reliable known records of Leadbeater's Possum (smaller, shaded patches).

multi-aged stands typically occur on topographically shaded sites. This probably reflects reduced fire intensity on these sites because of lower surface radiation and hence lower evaporation and consequently an improved water balance. Multi-aged stands are of interest in montane ash environments as, all other factors being equal, they provide a more sustained supply of nesting sites in hollow trees for Leadbeater's Possum. Figure 2 shows how the probability of multi-aged stands varies with incoming short-wave radiation.

\section{Micro-scale}

The focus of studies of animal distributional behaviours at the micro-scale is the distribution of colonies of Leadbeater's

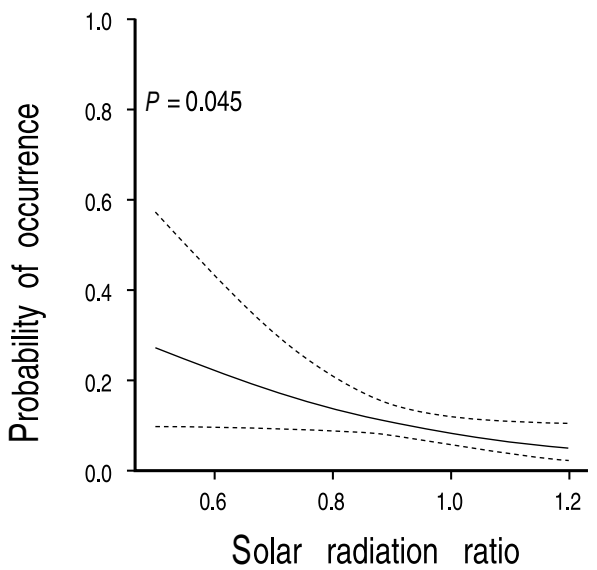

Figure 2 Modelled response of the multi-agedness of Mountain Ash stands to terrain-modified solar radiation. The relationship is from a logistic regression analysis correlating the probability of multiagedness on a site with values for solar radiation ratio (modified from Lindenmayer et al., 1999).

Possum. The presence of Leadbeater's Possum at more than 150,3 ha sites, was determined from surveys of the species throughout the Central Highlands of Victoria. More than thirty measures of the vegetation structure and plant species composition were recorded at these survey sites. Logistic regression modelling revealed that sites most likely to support Leadbeater's Possum were those with a high basal area of Acacia spp. and numerous trees with hollows (Fig. 3). Colonies of Leadbeater's Possum make nests in large trees with hollows and the number of these types of stems is probably a reflection of the availability of nest sites (Lindenmayer et al., 1991b). Measures of the basal area of Acacia spp. provide an estimate of the abundance of food for the species (Smith, 1984b). The performance of the logistic regression model developed from statistical analyses of data from the initial 150 sites was tested on a new and independent dataset comprising fifty-five additional 3 ha survey sites (Lindenmayer et al., 1994b). These analyses showed the model performed well when subjected to rigorous statistical testing.

Large areas of the Central Highlands of Victoria support few or no hollow-bearing trees (Lindenmayer et al., 1991c, 1997), and/or a limited quantity of Acacia spp. trees in the forest understorey. Thus, the absence of these key attributes of stand structure is an important factor contributing to the absence of Leadbeater's Possum from many areas of montane ash forest (Lindenmayer \& Cunningham, 1996).

Nano-scale

Nest building and group huddling to assist thermoregulation and energy conservation are some of the important nano-scale patterns of animal distributional behaviour exhibited by Leadbeater's Possum. At this scale, relationships have been established between the characteristics of 

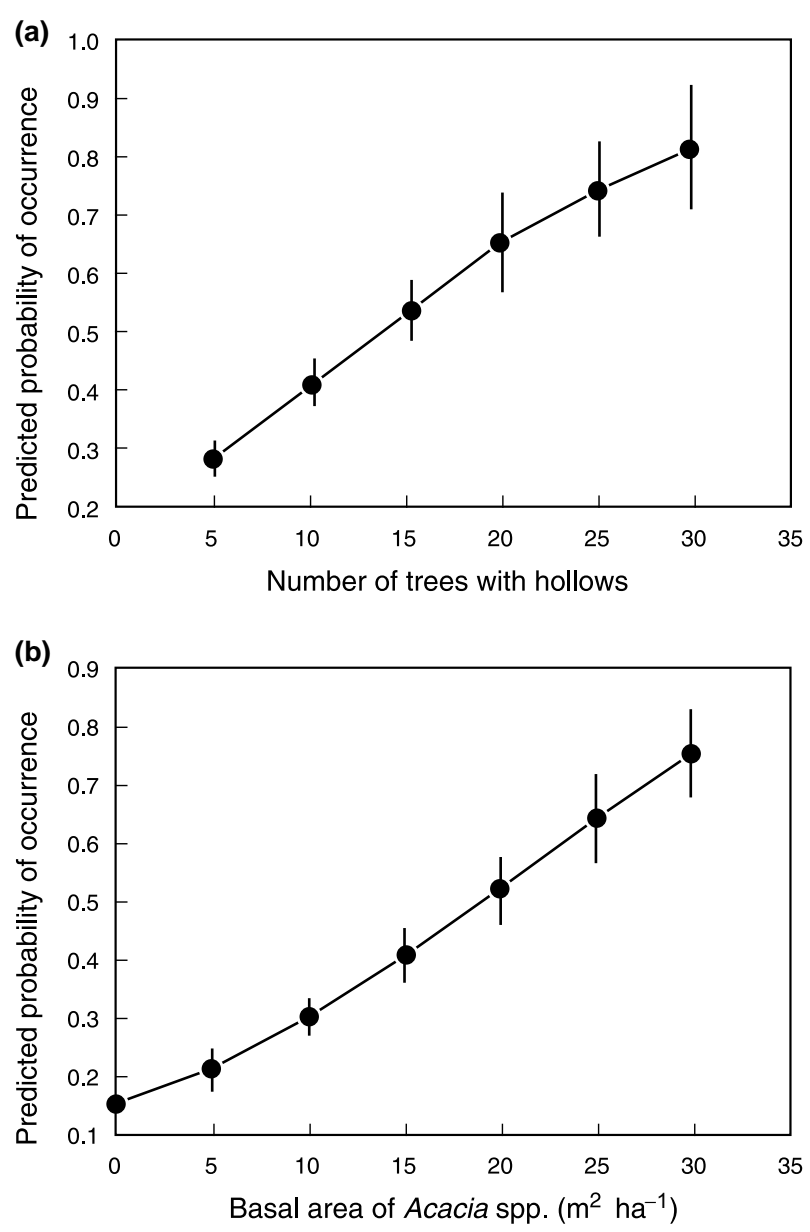

Figure 3 Probability of occurrence of Leadbeater's Possum (lower and upper values for the $95 \%$ confidence interval) predicted from a logistic regression model of the presence and absence of the species in the montane ash forests of the Central Highlands of Victoria (see text). Part a shows the nature of the logistic relationship for the number of trees with hollows on a 3-ha site and the probability of occurrence of Leadbeater's Possum. Part b shows the nature of the logistic relationship for the basal area of Acacia spp. in the understorey and the probability of occurrence of Leadbeater's Possum. Predicted values have been derived for the mean values for the other parameter in the statistical relationship (modified from Lindenmayer et al., 1991b).

hollow-bearing trees and their occupancy by individual animals (Lindenmayer et al., 1991d,e). Statistical analysis indicated that trees with hollows most likely to be occupied by Leadbeater's Possum were those that: (1) have short, large diameter stems, (2) contain numerous obvious holes and (3) are surrounded by a large quantity of dense vegetation ( $=\mathrm{a}$ high access score) (Lindenmayer et al., 1991d). The nest tree model developed for Leadbeater's Possum performed well when subject to rigorous statistical testing on a new data-set comprised of 400 trees with hollows (Lindenmayer et al., 1994b).

\section{Modelling the spatial distribution of Leadbeater's Possum}

In the preceding section we identified the responses of Leadbeater's Possum in terms of the intersection between hierarchically scaled distributional behaviours and measures and indices of the primary environmental resources at the five levels in our environmental hierarchy. In some cases, statistical models have been generated that quantified the relationship between the distribution of the animal and the impinging environmental conditions. Such quantitative models can be used to make a prediction of the species' occurrence at the specified level of distributional behaviour. In this section, we use the functions discussed above to generate scale-specific spatial predictions of the occurrence of Leadbeater's Possum.

The BIOCLIM system (Nix, 1986) generates estimates of long-term mean monthly climatic variables at any point in a region that can be specified by latitude, longitude and elevation. The BIOCLIM is based on mathematical interpolations of meteorological data using thin plate smoothing splines as developed by Hutchinson \& Bischoff (1983), Hutchinson (1991, 1995). This system can be used to generate a climatic profile for a species by estimating climatic parameters at a network of sites that sample the taxon's distribution. Gridded estimates of the climatic parameters can be generated on a landscape-wide basis by resolving the interpolation surfaces onto each grid point in a digital elevation model (Mackey et al., 1988; Nix \& Switzer, 1991).

The BIOCLIM can be used to predict a species' mesoscaled climatic domain. This is achieved by comparing its climate profile with the gridded estimates of climatic. The result of this procedure is a file of geo-referenced grid points whose climatic conditions match those summarized in the climatic profile of the target species. These data can be input to a GIS and the location of the matched cells plotted, highlighting the geographical distribution of the potential climatic domain of the target species.

The BIOCLIM system has been used to examine the climatic domain of a variety of taxa (see review by Burgman \& Lindenmayer, 1998). It was applied to species location data for Leadbeater's Possum by Lindenmayer et al. (1991a). These analyses generated the climatic profile given in Table 2 . The potential, meso-scaled climatic domain of Leadbeater's Possum is shown in Fig. 4. Grid matching at the maximum-minimum, and 10-90\%, levels in the bioclimatic profile gave, respectively, a predicted 'range' and 'core' distribution. The predicted core distribution of Leadbeater's Possum was confined to the Central Highlands of Victoria and closely resembled that of the current known distribution limits of the species. However, the predicted range distribution was based on a wider set of values than those for the core distribution, and it included areas that supported marginally suitable bioclimatic conditions for Leadbeater's Possum. Several of these areas were outside the Central Highlands of Victoria, and thus outside the present known distribution of the species. Intensive field 
Table 2 The bioclimatic envelope of Leadbeater's Possum. Homocline matching has been based on minimum-maximum values (predicted range distribution) and 10-90\% values (predicted core distribution) (see text and Fig. 4)

\begin{tabular}{|c|c|c|c|c|c|}
\hline \multirow[b]{2}{*}{ No. } & \multirow[b]{2}{*}{ Bioclimatic Index } & \multicolumn{4}{|c|}{ Profile value } \\
\hline & & Min & $10 \%$ & $90 \%$ & $\operatorname{Max}$ \\
\hline 1. & Annual mean temperature $\left({ }^{\circ} \mathrm{C}\right)$ & 5.79 & 8.75 & 11.95 & 14.29 \\
\hline 2. & Annual mean maximum temperature $\left({ }^{\circ} \mathrm{C}\right)$ & 10.10 & 13.22 & 17.37 & 19.40 \\
\hline 3. & Annual mean minimum temperature $\left({ }^{\circ} \mathrm{C}\right)$ & 1.49 & 4.18 & 6.82 & 9.53 \\
\hline 4. & Maximum diurnal temperature range $\left({ }^{\circ} \mathrm{C}\right)$ & 11.35 & 12.06 & 14.84 & 15.62 \\
\hline 5. & Mean temperature of the warmest month $\left({ }^{\circ} \mathrm{C}\right)$ & 12.58 & 15.60 & 18.32 & 20.07 \\
\hline 6. & Mean temperature of the coldest month $\left({ }^{\circ} \mathrm{C}\right)$ & -0.34 & 2.66 & 6.36 & 9.31 \\
\hline 7. & Mean seasonal range (index 5-index 6$)\left({ }^{\circ} \mathrm{C}\right)$ & 10.34 & 11.88 & 12.98 & 13.11 \\
\hline 8. & Isotherm seasonality (mean diurnal range - mean seasonal range) & 0.54 & 0.57 & 0.65 & 0.67 \\
\hline 9. & Maximum temperature of the hottest month $\left({ }^{\circ} \mathrm{C}\right)$ & 18.08 & 21.40 & 25.20 & 26.81 \\
\hline 10. & Minimum temperature of the coldest month $\left({ }^{\circ} \mathrm{C}\right)$ & -3.07 & -0.31 & 2.72 & 5.76 \\
\hline 11. & Annual temperature range (index 9 -index 10$)\left({ }^{\circ} \mathrm{C}\right.$ ) & 19.17 & 21.28 & 23.02 & 23.36 \\
\hline 12. & Mean temperature of wettest quarter $\left({ }^{\circ} \mathrm{C}\right)$ & 1.15 & 4.14 & 8.55 & 11.89 \\
\hline 13. & Mean temperature of the driest quarter $\left({ }^{\circ} \mathrm{C}\right)$ & 11.58 & 14.59 & 17.30 & 19.04 \\
\hline 14. & Mean temperature of the warmest quarter $\left({ }^{\circ} \mathrm{C}\right)$ & 11.59 & 14.66 & 17.49 & 19.04 \\
\hline 15. & Mean temperature of the coldest quarter $\left({ }^{\circ} \mathrm{C}\right)$ & 0.29 & 3.26 & 6.82 & 9.70 \\
\hline 16. & Annual precipitation $(\mathrm{mm})$ & 1008 & 1344 & 1712 & 1799 \\
\hline 17. & Precipitation of the wettest month $(\mathrm{mm})$ & 108 & 143 & 197 & 202 \\
\hline 18. & Precipitation of the driest month $(\mathrm{mm})$ & 58 & 68 & 88 & 94 \\
\hline 19. & Annual precipitation range (index $17-$ index 18$)(\mathrm{mm})$ & 42 & 70 & 120 & 131 \\
\hline 20. & Seasonality index [index 19/(index 16/index 12)] & 0.50 & 0.58 & 0.87 & 0.98 \\
\hline 21. & Precipitation of the wettest quarter $(\mathrm{mm})$ & 303 & 420 & 559 & 564 \\
\hline 22. & Precipitation of the driest quarter $(\mathrm{mm})$ & 193 & 226 & 276 & 285 \\
\hline 23. & Precipitation of the warmest quarter $(\mathrm{mm})$ & 204 & 238 & 293 & 297 \\
\hline 24. & Precipitation of the coldest quarter (mm) & 288 & 392 & 545 & 558 \\
\hline
\end{tabular}

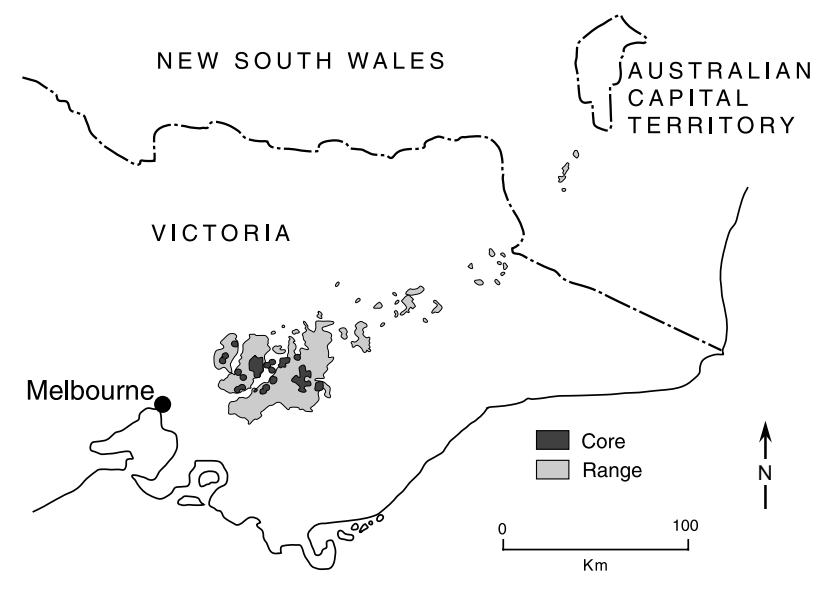

Figure 4 Meso-scaled map of the predicted core distribution (dark areas) and range distribution (hatched areas) of Leadbeater's Possum based on analyses using the BIOCLIM system (sensu Nix, 1986; Nix \& Switzer, 1991). The predicted core distribution is based on homoclime matching for cells matched at the $10-90 \%$ levels in the climate profile of the species (see Table 2). The predicted range distribution is based on homoclime matching for cells matched at the mimimum-maximum levels in the climate profile of the species (see Table 2).

surveys failed to detect the species within any areas outside the Central Highlands of Victoria (Lindenmayer et al., 1991a).
Digital terrain analysis based on digital elevation models enable predictions of animal distribution to be generated on a landscape-wide basis as a function of the topo-scaled slope and surface radiation. While meso-scaled climate can be satisfactorily gridded at a grid resolution of $1-5 \mathrm{~km}$, terrain attributes such as slope and surface radiation require access to a digital elevation model with a grid resolution of $10-40 \mathrm{~m}$. For this paper, we used a $30-\mathrm{m}$ resolution elevation model to generate estimates of radiation (using the modelling procedure described in McKenney et al., 1999). These topo-scaled estimates were coupled to the statistical relationships detailed in Fig. 2 to generate the probability of occurrence of multi-age forest throughout an area that encompasses the Watts Creek watershed (Fig. 5). As noted above, places with a high probability of supporting multi-aged stands are areas characterized by a greater availability of suitable nesting sites for Leadbeater's Possum.

Micro-scale and nano-scale coverage of extant vegetation patches is traditionally mapped using air-photo interpretation (e.g. Woodgate et al., 1994) (more recently, digital sources such as the satellite-borne Landsat Thematic Mapper sensor have been used to generate vegetation coverages). Figure 6 shows at the micro-scale the spatial distribution of potentially suitable vegetation patches for Leadbeater's Possum in the Murrindindi and Steavenson Forest Blocks, based on data derived from aerial photography coupled with on-ground stand inventory surveys of montane ash forests. Similar procedures enabled identification of the boundaries 

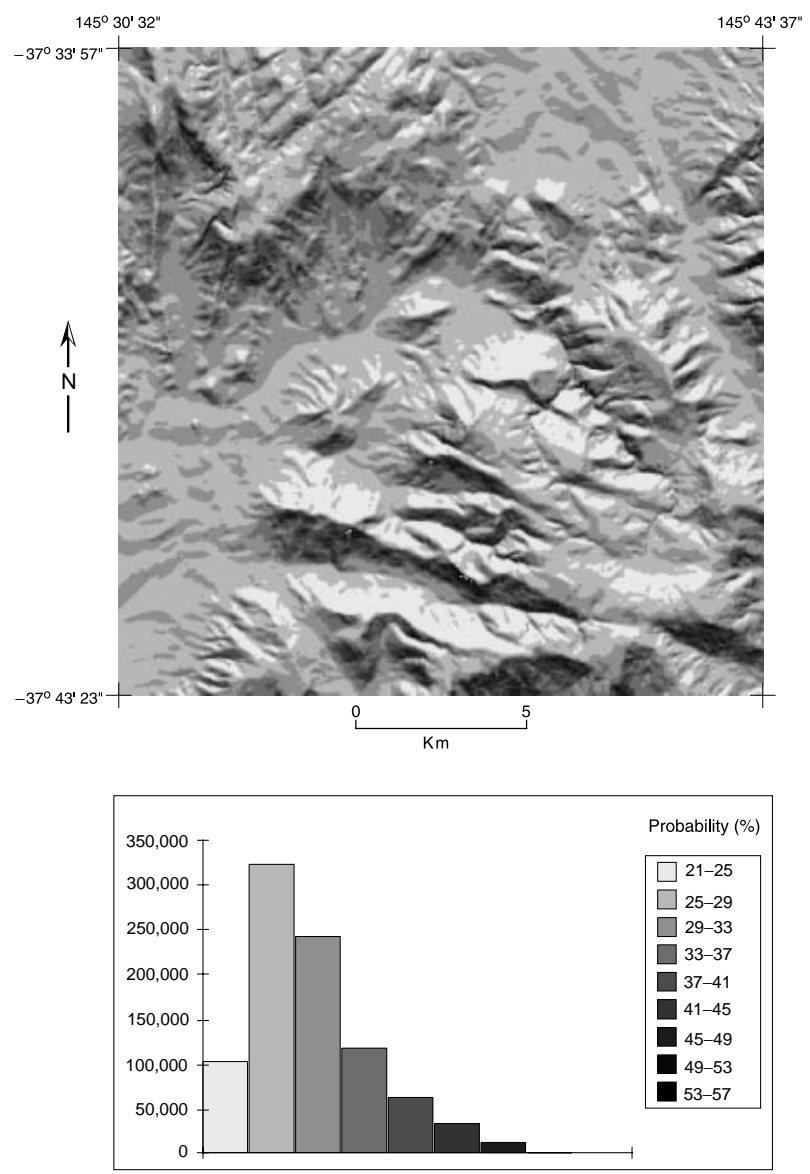

Figure 5 Topo-scaled maps showing the spatial prediction of probability of multi-age forest as a function of terrain-modified radiation for an area that encompasses Watts Creek watershed in the Central Highlands of Victoria. Probabilities are predicted on a scale of $0.0-1.0$. The resolution of the gridded predictions is c. $30 \mathrm{~m}$. The histogram shows the number of grid cells predicted to have a given probability.

Figure 6 Micro-scaled map showing the spatial structure of potentially suitable patches of vegetation for Leadbeater's Possum within the Murrindindi Forest Block (top) and the Steavenson Forest Block (bottom) in the Central Highlands of Victoria. The Murrindindi Forest Block covers an area of $c .3500$ ha and the area of the Steavenson Forest Block is c. 5500 ha. The patches are differently shaded in recognition of the fact that forest with suitable structural features for Leadbeater's Possum can be found in old growth, mixed aged or regrowth forest with numerous large old trees with cavities (see text). The spatial location of patches in both forest blocks has been derived from on-ground forest inventory and aerial photography (modified from Lindenmayer \& Possingham, 1995a). The lines on the map show the locations of riparian reserves supporting old growth habitat that may support Leadbeater's Possum. of patches and within them at the nano-scale the point locations of above-canopy hollow-bearing trees in landscapes (Fig. 7). These data have been stored in a GIS (Smith
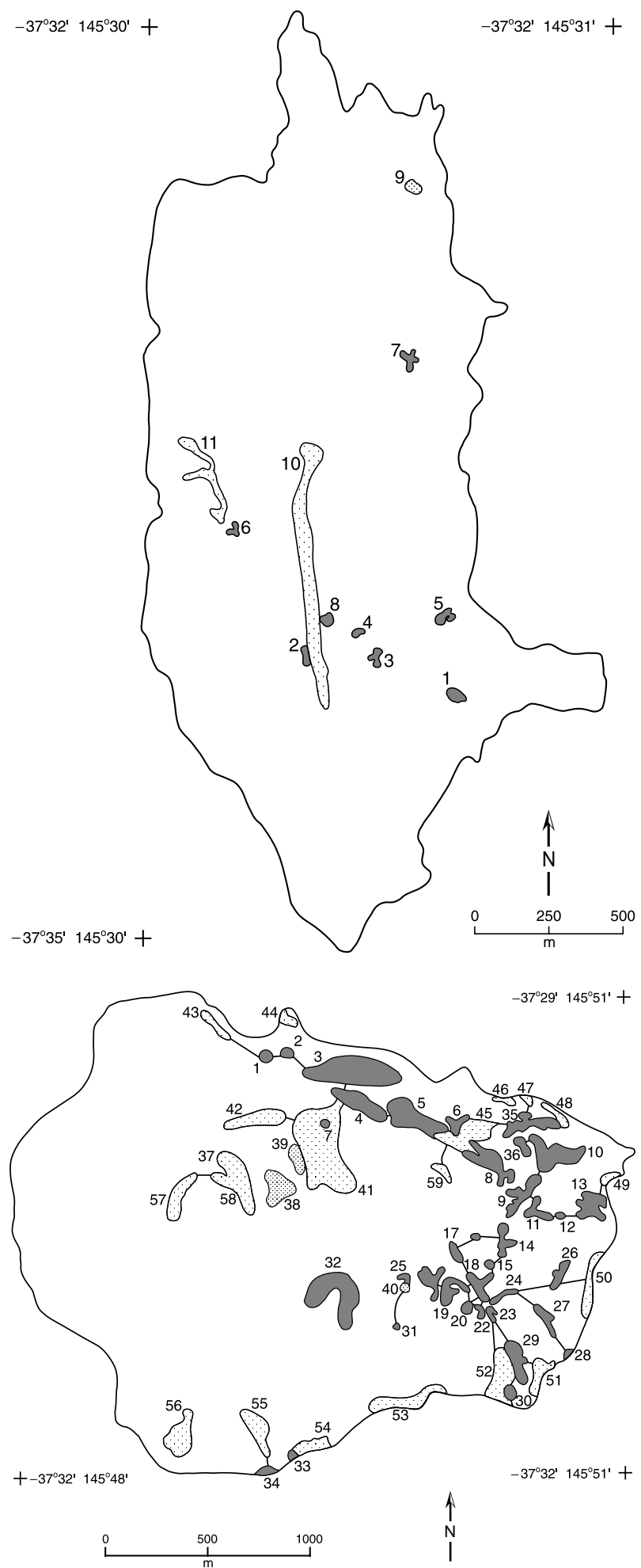
\& Macfarlane, 1994) which was interrogated to produce the maps shown in Figs 6 and 7.

The accuracy of aerial photography (and Landsat-derived vegetation classifications) is limited as it does not provide quantitative data on below-canopy vegetation characteristics. Hence, the spatial distribution of critical nano-scaled factors for Leadbeater's Possum remains largely unknown, in particular: (1) the abundance and taxonomic composition of Acacia spp. trees in the understorey, and (2) the prevalence of large trees with hollows underneath the tree canopy. Therefore, data are not available on some aspects of intra-patch heterogeneity. This is particularly important for montane ash forests where there is considerable spatial heterogeneity in understorey vegetation (Mueck, 1990; Ough \& Ross, 1992; Lindenmayer \& Cunningham, 1996; Mueck et al., 1996) and large variations in primary productivity between stands dominated by the same species of overstorey tree.

It is important to note that the spatial predictions generated at each level in the environmental hierarchy are spatially nested - the bioclimatic domain (Fig. 4) spatially contains the multi-age forest predictions (Fig. 5), which contain the patches of suitable habitat in the forest blocks (Fig. 6), which in turn contain the distributions of hollowbearing live and dead emergent trees (Fig. 7).

\section{Linking information across levels}

Our framework for modelling the distribution of organisms allows for coupling and integration between levels in the proposed environmental hierarchy. Notably, statistical approaches for the analysis of nested data sets such as Restricted Maximum Likelihood Estimation (REML) (Robinson, 1991) enable the development of robust statistical relationships using multilevel data. Coupling and integration between levels in the hierarchy is readily demonstrated from our work on Leadbeater's Possum. For example, micro-scale data gathered from stands and nanoscale attributes measured on individual trees with hollows can be integrated to derive a multilevel model describing the probability of a potential nest tree being occupied within a given stand. For arboreal marsupials like Leadbeater's Possum, the probability of occupancy is significantly $(P<0.05)$ related both to tree (nano-scale) characteristics (stem shape and number of cavities), the number and spatial distribution of potentially suitable trees with such characteristics within a stand (i.e. micro-scale tree spacing), and micro-scale stand attributes like the basal area of Acacia spp. (Lindenmayer et al., 1990b). Hence, such an approach makes it possible to simultaneously account for those variables at the tree and site levels which significantly influence occupancy. The biological meaning of the interrelationships between the different levels in the environmental hierarchy is clear-stems with potentially suitable tree-level (nano-scale) characteristics will not be occupied if surrounding stand-level (micro-scale) conditions are unsuitable.

Statistical approaches are available to examine interrelationships between other levels in our hierarchical framework. For example, analyses of extensive data gathered from individual stands (the micro-scale; see above) helped identify the habitat requirements of Leadbeater's Possum (Lindenmayer et al., 1991b, 1994b). Information on habitat requirements of the species can, in turn, be used to determine the spatial distribution of patches of potentially suitable habitat at a topo-scale (e.g. Lindenmayer \& Lacy, 1995; Lindenmayer \& Possingham, 1995a). Indeed, such empirical relationships at a micro-scale are crucial for predicting and mapping spatial patterns at the topo-scale. Methods for spatial statistics such as variograms and correlograms can be then employed to test for patterns of spatial dependence in habitat patch occupancy among potentially suitable patches. Similarly, statistical methods for spatial autocorrelation in regression analysis are available for examining variables across geographical space (e.g. Legendre, 1993; Smith, 1994). Such approaches provide robust probabilistic insights into whether processes like meta-population dynamics are taking place (Koenig, 1998). This is because meta-population theory predicts that suitable patches close to occupied suitable patches have a higher probability of being occupied than isolated ones (Hanski, 1994) - a process yielding strong patterns of spatial dependence in patch occupancy. Hence, statistical methods like spatial autocorrelation can help integrate statistical relationships at the micro-scale with population processes at a topo-scale in our hierarchy.

Information on spatial dependence can be used in making spatial predictions of distribution patterns in two possible ways: (1) incorporation of additional terms in statistical relationships that account explicitly for spatial dependence (e.g. Cressie, 1991); or (2) the application of spatial smoothing routines (e.g. Hardle, 1990) that incorporate spatial dependence in a nonparametric way (see Lindenmayer et al., 1995). The former method is preferred but its application is often impeded by the lack of spatial data at fine scales. The latter enables the value of an observation at a particular point to be smoothed on the basis of the weighted average of observations from adjacent locations (Hardle, 1990; Lindenmayer et al., 1995). Hence, the statistical methods outlined above enable the influence of spatial processes to be included in empirical relationships within and between different levels in our hierarchical framework, and can be used to help make more realistic spatial predictions of animal distributional behaviours.

There are few studies of species distribution patterns which have explicitly accounted for spatial dependence or spatial autocorrelation (but see Smith, 1994). This is largely because suitable data sets are not available to facilitate appropriate analyses (Koenig, 1998). Such an investigation has been completed for the arboreal marsupial, Greater Glider (Petauroides volans), in the montane ash forests of the Victoria (Lindenmayer et al., 1995). A similar study of spatial dependence patterns is planned for Leadbeater's Possum and it will be undertaken as soon as suitable mapped spatial data on vegetation structure, particularly the basal area of understorey Acacia spp., are available.

Our framework also allows for the application of methods that facilitate integration between the different biological units that comprise the levels in our behavioural hierarchy. 

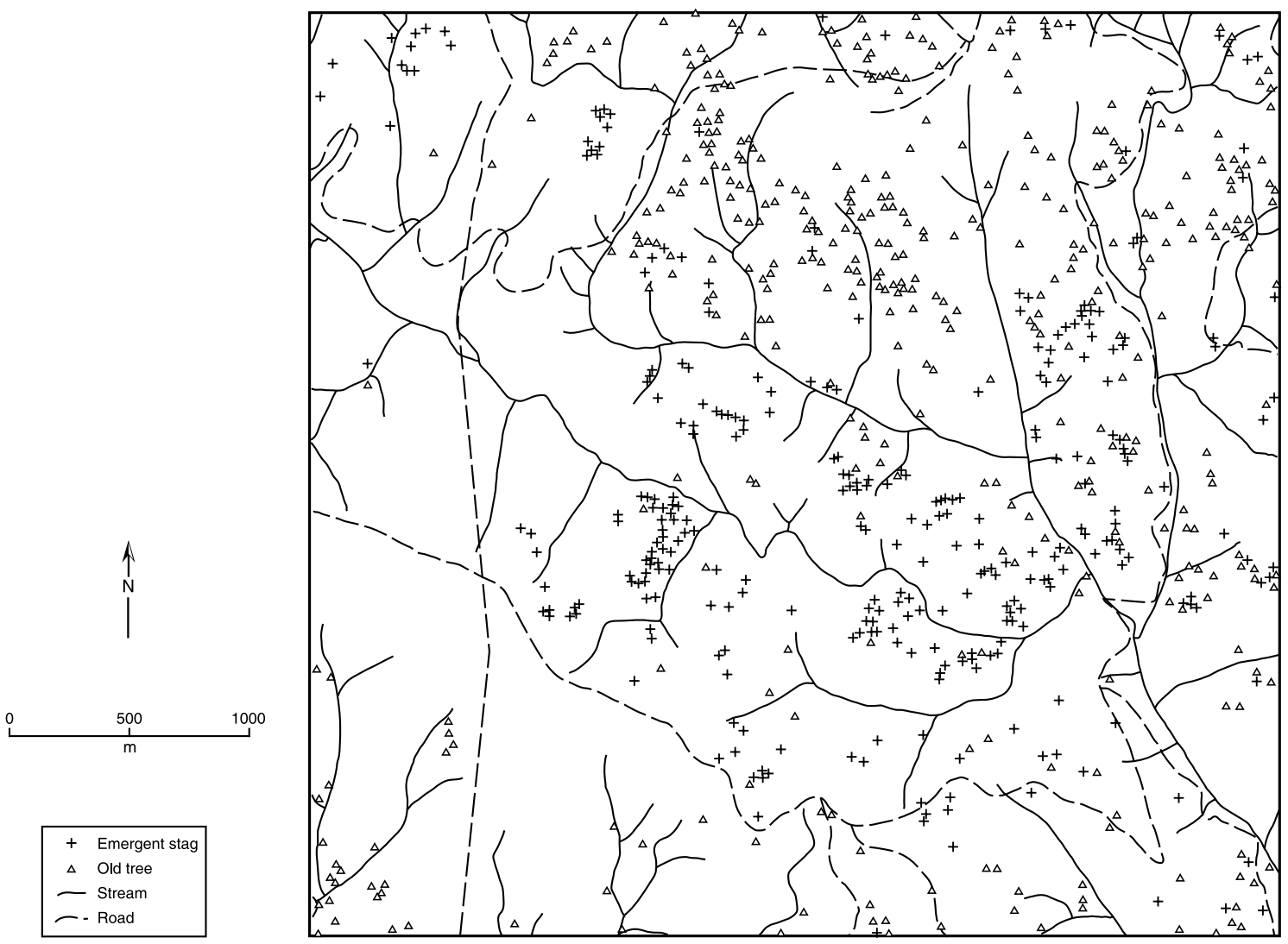

Figure 7 Nano-scaled map showing point locations of large living and dead trees with hollows that emerge above the canopy in an area of montane ash forests within the Ada Forest Block in the Central Highlands of Victoria. Emergent stags (denoted + ) are dead trees with hollows that emerge above the canopies of surrounding living young regrowth trees. Old trees (denoted with a triangle) are large single old growth stems with a living crown that overtops the crowns of the canopies of surrounding living young regrowth trees.

Welsh et al. (1996) describe a statistical method called ZeroInflated Poisson regression that can be used to combine data on the presence of a species and then given occurrence, its abundance. This enables, for example, spatial predictions to be generated based on coupling a presence/absence model of the species based on micro-scaled attributes with an abundance model of a colony derived as a function of nano-scaled characteristics.

\section{DISCUSSION}

The case study illustrates the feasibility of our proposed modelling framework when applied to a species with an extremely restricted distribution. The question remains as to the generic applicability of this framework. The generic capacity to predict spatial distributions is now widely recognized as being central to the conservation of biodiversity. For example, the Gap Analysis Program of the United State Geological Service (USGS, 2001) aims to provide regional assessments of the conservation status of native vertebrate species and natural land cover types and to facilitate the application of this information to land management activities.
A key objective of this programme is to map the predicted distributions of vertebrate species for the US. However, a number of factors must be considered when assessing how adequately the Leadbeater's Possum case study has tested the generic applicability of our modelling framework.

\section{Intra-species variability}

Our case study did not examine a species with a large geographical distribution. In such a case, it can be hypothesized that populations at the extreme ends of the range may exhibit different distributional behaviour-environment responses. In such circumstances, application of our framework would require either two independent modelling exercises (to capture both sets of population responses) or for field survey data to be sampled across the taxon's total range. The latter is our preferred option as we predict that the focus on defining responses to the primary environmental resources (rather than environmental and habitat features obvious to humans) is more likely to produce a model that reflects the species' physiological and ecological responses. 


\section{Temporal scales and the spatial distribution of animals}

The levels that characterize the behavioural and environmental hierarchies are defined by both spatial and temporal dimensions. However, here we have focused on predictive modelling in the spatial dimension only. While a lack of space prevents a detailed modelling treatment of the temporal components, they should be taken as implicit within our definition of each spatial level. For example, the meso-scaled climate models are based on daily weather records averaged over periods of 30-100 years (depending on the length of record). While temporal scales can be identified at each level, they do not necessarily have a similarly scaled spatial component. For example, in the case of migratory birds, there may not be strong congruence between the temporal and spatial components of migratory behaviour, as such animals may travel long distances in relatively short periods of time.

Nonetheless, the temporal scales over which the various categories of animal distributional behaviour occur also must be considered in generating predictive models. Hence, there are interactions between temporal and spatial components of animal distributional behaviour. Holling (1992) explicitly considered the temporal frequency of his six hierarchical levels, and this remains a task requiring further attention on our part. By way of example, in the case of Leadbeater's Possum, we can suggest the following: (1) At a nano-scale, individual animals may alter nocturnal patterns of foraging behaviour within minutes as a consequence of changes in the weather (Smith et al., 1982; Lindenmayer, 1996). Animals may move up to a $100-\mathrm{m}$ in this time, such as to return to a nest site. In addition, individual animals would rarely be expected to survive longer than 5 years in the wild (Lindenmayer, 1996). During this life-span, they may move over 1-3 ha in the natal territory. The distance that subadults then disperse to seek a new territory is not known but may be $1-5 \mathrm{~km}$. Genetic studies using highly variable microsatellite markers are presently underway to examine the dispersal capability of Leadbeater's Possum, and, in turn, estimate the distances animals traverse during dispersal. (2) At a micro-scale, the generation time of breeding colonies of animals is calculated to be c. 3.5-4 years (Lindenmayer et al., 1993c; Lindenmayer \& Lacy, 1995). The area encompassed by the overlapping home ranges of colony members is c. 3 ha (Smith, 1980; Lindenmayer \& Meggs, 1996). (3) In the absence of disturbance events, topo-scale fluctuations in meta-population dynamics (such as localized extinctions) and major changes in genetic variability in small, isolated populations may occur over several decades (Lindenmayer \& Lacy, 1995). Changes in distribution patterns at this scale may occur across entire forest blocks covering thousands of hectares (Lindenmayer \& Possingham, 1995a; McCarthy \& Lindenmayer, 2000). (4) Meso-scaled variations in range limits of the species may take place over thousands of years as a consequence of global climate change (Lindenmayer, 1989; Lindenmayer et al., 1991a). Changes in distribution patterns may exceed thousands of square kilometers in this time (Lindenmayer, 1989; Lindenmayer et al., 1991a).

\section{Applicability to other ecosystems}

Application of our hierarchically structured modelling framework requires a three step process: (1) the collection of field data about the distributional behaviour of a species, (2) statistical analyses that establish relationships between these data and the primary environmental resources and (3) coupling these functions to a geographical data base to derive a probabilistic prediction of their spatial distribution. These analyses need to be undertaken inclusive of (where feasible) all levels in both the behavioural and environmental hierarchies.

Although our case study focused on one species, we are confident that the modelling framework should apply to other terrestrial vertebrates. Like Leadbeater's Possum, a set of scaled levels in distributional behaviour will be apparent in other species - although the importance of a given level will vary between taxa (e.g. the population level may be more important than the colony level); as will the geographical scale defining each level.

It is axiomatic that all species are dependent on the same primary environmental resources as defined here. Furthermore, the distribution and availability of the primary environmental resources in all terrestrial ecosystems involve our five hierarchical scales. However, the influence and nature of meso- and topo-scaled processes do vary between ecosystems. For example, in the relatively flat seasonally dry savanna of northern Australia, groundwater resources are biologically critical in the dry season. Topo-scaled processes associated with surface water runon/runoff and micro-scaled processes related to vegetation shading can be less important in defining critical water regimes compared with dry season groundwater discharge into water holes and springs (Horn, 1995). Thus, while the basic concept of tracking how animals respond to the hierarchically structured delivery of primary environmental resources remains valid in all terrestrial ecosystems, the critical process scales that determine the distribution and availability of water and nutrients can be complex and landscape-specific.

Other researchers have argued the value of viewing ecological phenomena as a continuum (see Forman, 1964; Jarvis \& McNaughton, 1986; Pickett et al., 1989). Our analyses, and those of Holling (1992), suggest otherwise. However, even if these authors are correct, it is logisitically impossible to investigate a continuum of phenomena. As discussed by Allen \& Hoekstra (1992), all scientific modes of investigation demand that a window of observation is defined based on a specified set of space/time scales, thereby consigning certain phenomena to the background while identifying the system boundaries, components and interactions that are the key foci of study. 
We are aware, however, that there are processes operating at intervening levels to the five we have identified. Given this, our levels could also be viewed as nodes in a continuum around which clusters of similarly scaled processes can be identified. There may well be additional levels and processes necessary to model the distribution of certain animal species. Indeed, various authors have argued the need for preliminary (pilot) analyses to determine the appropriate scales of investigation (see Gilmore, 1990; Hoekstra et al., 1991; Cale \& Hobbs, 1994; Schneider, 1994; Bellehumeur \& Legendre, 1998). The extent to which our hierarchical modelling framework is, or is not, generic can only be determined through ongoing empirical investigations. However, even if additional levels to those suggested here are needed, our framework provides a logical and consistent starting point from which to work.

\section{Disturbance regimes and other factors}

We have not explicitly discussed the role of disturbance regimes in our analytical framework, although it is clear that such processes can be important in shaping the distribution patterns of animals (e.g. Williams \& Gill, 1995; Baker, 1997). For example, fire plays a critical role in shaping the distribution of Leadbeater's Possum, both directly and indirectly through its effect on the structure and composition of habitat in montane ash forests (Lindenmayer \& Possingham, 1995a, b; Lindenmayer et al., 1999). Prediction of the future distribution of Leadbeater's Possum, therefore requires, among other things, the ability to simulate the space/time variability in the fire regime on a landscape-wide basis.

The distribution patterns of parasites and competitors for a given taxon will also be subject to the scale-dependent delivery of primary environmental resources, and therefore they should also exhibit scale-related behaviours (e.g. Anderson, 1972). Extending our framework to include such competitive interactions remains a task for the future, but we suggest that it will require the application of landscape-wide, dynamic agent-based simulation models such as described by Su \& Mackey (1997).

\section{CONCLUSIONS}

It is critical to recognize that the distribution and availability of the primary environmental resources is an integration of both physical and biological processes. Furthermore, these processes occur at distinctive levels in a scaled hierarchy. In the case of the spatial distribution of Leadbeater's Possum, the effects of scale-related variability in the primary environmental resources include: (1) influencing the broad distribution patterns of the montane ash forests within which the species is virtually confined, (2) exerting constraints on the animal's physiological processes thereby defining its potential range at a meso-scale, (3) exerting direct and indirect effects on forest stand architecture as well as patterns of primary productivity and understorey plant species composition, (4) influencing the availability of food resources [e.g. flows of plant exudates (Hansford, 1985)], (5) effecting patterns of cavity ontogeny as well as thermal and moisture conditions within individual tree hollows, and hence (6) influencing physiological activities among colonies of animals such as thermoregulatory behaviour inside the nest.

Studying a species distribution and abundance involves engaging with various levels of ecological organization and their environmental relations (Urban et al., 1987; Lugo, 1996). Investigations at a particular level often leads to different types of studies that are typically treated as relatively disparate subdisciplines such as biogeography, environmental modelling, landscape ecology and population biology - each of which typically has a relatively narrow window of observation (Lawton \& Jones, 1993). Our analytical framework provides a basis for integrating data drawn from empirical studies of differently scaled processes within an explicit theoretical construct of how animals interact with their environment. The case study on Leadbeater's Possum indicated that the knowledge gained from a range of interrelated studies is considerably greater than would be derived from any single investigation completed at one scale. Indeed, data at any one hierarchical level was required to inform patterns at another (e.g. the use of habitat information at a micro-scale to define suitable patches at a topo-scale). There is much to be gained from being cognizant of the complex interactions between the multi-scaled factors that influence the distribution patterns of species.

\section{ACKNOWLEDGMENTS}

This paper is based on an extensive series of field-based studies on Leadbeater's Possum that have been completed in collaboration with $\mathrm{Mr}$ R. Cunningham, Prof. H.A. Nix, Prof. H. Possingham, Dr M. Tanton, Ms C. Donnelly, Dr R. Lacy, Associate-Professor A. Smith, Ms J. Smith and many other colleagues. The Victorian Department of Natural Resources and Environment kindly allowed access to spatial information on habitat patchiness in the Central Highlands of Victoria. I. Mullen and a range of other colleagues kindly provided comments that improved earlier versions of the manuscript. I. Mullen also provided invaluable technical assistance in the production of some of the figures. This paper is dedicated to the memory of Prof. Kevin Lafferty. The conceptual origin of this paper owes much to a conversation with Prof. Lafferty regarding hierarchy theory as defined in Author Koestler's book The Ghost in the Machine.

\section{REFERENCES}

Allen, T.F.H. \& Hoekstra, T.W. (1992) Toward a unified ecology. Columbia University Press, New York.

Anderson, R.C. (1972) The ecological relationships of meningeal worm and native cercids in North America. Journal of Wildlife Diseases, 8, 304-310.

Attiwill, P.M. \& Leeper, G.W. (1987) Forest soils and nutrient cycles. Melbourne University Press, Melbourne, Australia.

Austin, M.P., Nicholls, A.O. \& Margules, C.R. (1990) Measurement of the realized qualitative niche: environmental 
niches of five Eucalyptus species. Ecological Monographs, 60, 161-177.

Baker, J. (1997) The decline, response to fire, status and management of the Eastern Bristlebird. Pacific Conservation Biology, 3, 235-243.

Bellehumeur, C. \& Legendre, P. (1998) Multiscale sources of variation in ecological variables: modeling spatial dispersion, elaborating sampling designs. Landscape Ecology, 13, 15-25.

Blakers, M., Davies, S.J. \& Reilly, P.N. (1984) The atlas of Australian birds. Royal Australasian Ornithithological Union. Melbourne University Press, Melbourne, Australia.

Block, W.M. \& Brennan. L.A. (1993) The habitat concept in ornithology. Theory and applications. Current ornithology, Vol. 11 (ed. D.M. Power), pp. 35-91. Plenium Press, New York.

Booth, R. (1994) Possums and gliders husbandry and medicine. Wildlife: The T.G. Hungerford refresher course for veterinarians. Proceedings 233. 19-23 September 1994, pp. 429434. Western Plains Zoo, Dubbo, NSW.

Briggs, D. \& Smithson, P. (1992) Fundamentals of physical geography. Routledge, London.

Brown, J.H. (1984) On the relationship between distribution and abundance. American Naturalist, 124, 255-279.

Burgman, M.A. \& Lindenmayer, D.B. (1998) Conservation biology for the Australian environment. Surrey Beatty and Sons, Chipping Norton, Sydney.

Burroughs, P.A. (1986) Principles for geographic information systems for land resource assessment. Oxford University Press, New York.

Calder, T.G., Golding, B.G. \& Manderson, A.D. (1983) Management for arboreal species in the Wombat State Forest. Environmental Studies Report No. 16. Monash University Graduate School of Environmental Science, Melbourne, Australia.

Cale, P.G. \& Hobbs, R.J. (1994) Landscape heterogeneity indices: problems of scale and applicability, with particular reference to animal habitat description. Pacific Conservation Biology, 1, 183-193.

Carter, R.N. \& Prince, S.D. (1988) Distribution limits from a demographic viewpoint. Plant population ecology (eds A.J. Davey, M.J. Hutchings and A.R. Watkinson), pp. 165-184. Blackwell, Oxford, UK.

Caughley, G. (1978) The analysis of vertebrate populations. John Wiley and Sons, London, UK.

Christian, C.S. \& Stewart, G.A. (1953) General report on survey of Katherine-Darwin Region, 1946. Land Research Series 1. Commonwealth Scientific and Industrial Research Organisation, Australia.

Cressie, N. (1991) Statistics for spatial data. Wiley, New York.

Davey, S.M. \& Stockwell, D.R. (1991) Incorporating wildlife habitat into an AI environment: concepts, theory and practicalities. AI Applications, 5, 59-104.

Eltahir, E.A.B. \& Bras, R.L. (1994) Precipitation recycling in the Amazon Basin. Quarterly Journal of Royal Meteorological Society, 120, 861-880.

Elton, C.S. (1927) Animal ecology. Meuthen, London.

Fitzpatrick, E.A. \& Nix, H.A. (1970) The climatic factor in grassland ecology. Australian grasslands (ed. R.M. Moore), pp. 3-26. Australian National University Press, Canberra, Australia.
Forman, R.T. (1964) Growth under controlled conditions to explain the hierarchical distributions of a moss, Tetraphis pellucida. Ecological Monographs, 34, 1-25.

Forman, R.T. (1995) Land mosaics. The ecology of landscapes and regions. John Wiley and Sons, New York.

Forman, R.T. \& Godron, M. (1986) Landscape ecology. John Wiley and Sons, New York.

Franklin, J. (1995) Predictive vegetation mapping: geographic modeling of biospatial patterns in relation to environmental gradients. Progress in Physical Geography, 19, 474-499.

Gallant, J.C. \& Wilson, J.P. (1996) TAPES-G: a grid-based terrain analysis program for the environmental sciences. Computers and Geosciences, 22, 713-722.

Gillier, P.S. \& Gee, J.H.R. (1987) The analysis of community organisation: the influence of equilibrium, scale and terminology. Organisation of communities past and present (eds J.H. Gee and P.S. Giller), pp. 519-542. Blackwell Scientific Publications, Oxford, UK.

Gilmore, A.M. (1990) Plantation forestry: conservation impacts on terrestrial vertebrate fauna. Prospects for Australian plantations (eds J. Dargavel and N. Semple), pp. 377-388. Centre for Resource and Environmental Studies, The Australian National University, Canberra, Australia.

Golley, F.B. (1983) Nutrient cycling and nutrient conservation. Ecosystems of the world, vol. 14A: tropical rainforest ecosystems: structure and function (ed. F.B. Golley), pp. 137-156. Elsevier, New York.

Gorshkov, V.G. (1995) Physical and biological basis of life stability: man, biota, environment. Springer-Verlag, Berlin.

Grayson, R.B., Finlayson, B.L., Jayasuriya, M.D. \& O'Shaughnessy, P.J. (1992) The effects of clearfelling and harvesting operations on the quality of streamflow from a mountain ash forest. Land and Water Resources Research and Development Corporation Project UME 1. Land Water Resources Research and Development Corporation, Canberra, Australia.

Gutzwiller, K.J. \& Anderson, S.H. (1987) Multiscale associations between cavity-nesting birds and features of Wyoming streamside woodlands. The Condor, 89, 534-548.

Hansford, M.J. (1985) A study of Acacia gummosis. BSc. Hons. Thesis. La Trobe University, Melbourne, Australia.

Hanski, I. (1994) Patch occupancy dynamics in fragmented landscapes. Trends in Evolution and Ecology, 9, 131-134.

Hardle, W. (1990) Applied nonparametric regression. Econometric Society Monograph Series. Cambridge University Press, New York.

Harmon, M., Franklin, J.F., Swanson, F., Sollins, P., Gregory, S.V., Lattin, J.D., Anderson, N.H., Cline, S.P., Aumen, N.G., Sedell, J.R., Lienkaemper, G.W., Cromack, K. \& Cummins, K. (1986) Ecology of coarse woody debris in temperate ecosystems. Advances in Ecological Research, 15, 133-302.

Harper, J.L. (1977) Population biology of plants. Academic Press, London, UK.

Harrison, B.A. \& Jupp, D.L.B. (1990) Introduction to image processing. CSIRO, Melbourne, Australia.

Hoekstra, T.W., Allen, T.F. \& Flather, C.H. (1991) Implicit scaling in ecological re-search. Bioscience, 38, 489-508.

Holling, C.S. (1992) Cross-scale morphology, geometry, and dynamics of ecosystems. Ecological Monographs, 62, 447-502. 
Hope, G.S. (1984) Australian environmental change: timing, directions, magnitudes and rates. Quaternary extinctions: a prehistoric revolution (eds P.S. Martin and R.G. Klein), pp. 681-689. University Arizona Press, Tuscon, AZ.

Horn, A.M. (1995) Surface water resources of Cape York Peninsula. Cape York Planning and Land Use Study. Individual Reports - Land Use. Queensland State Government, Queensland.

Hutchinson, M.F. (1991) Climate analyses in data sparse regions. Climatic risk in crop production (eds R.C. Muchow and J.A. Bellamy), pp. 55-71. CAB International, Wallingford, UK.

Hutchinson, M.F. (1995) Interpolating mean rainfall using thin plane smoothing splines. International Journal of GIS, 9, 385-403.

Hutchinson, M.F. \& Bischoff, R.J. (1983) A new method for estimating the spatial distribution of mean research and annual rainfall applied to the Hunter Valley, NSW. Australian Meteorology Magazine, 31, 179-184.

Jaquet, N. (1996) How spatial and temporal scales influence understanding of Sperm Whale distribution: a review. Mammal Review, 26, 51-65.

Jarvis, P.G. \& McNaughton, K.G. (1986) Stomatal control of transpiration: scaling up from leaf to region. Advances in Ecological Research, 15, 1-49.

Kershaw, A.P. (1981) Quaternary vegetation and environments. Ecological biogeography of Australia (ed. A. Keast), pp. 83-101. Junk, The Hague, the Netherlands.

Koenig, W.D. (1998) Spatial autocorrelation in California land birds. Conservation Biology, 12, 612-619.

Krebs, C.J. (1978) The experimental analysis of distribution and abundance. Harper \& Row, New York.

Lawton, J.H. \& Jones, C.G. (1993) Linking species and ecosystem perspectives. Trends in Evolution and Ecology, 8, 311-313.

Laymon, S.A., Salwasser, H. \& Barrett, R.H. (1985) Habitat suitability index models: spotted owl. US Fish and Wildlife Service Biology Report, 82, 1-14.

Legendre, P. (1993) Autocorrelation: problem or new paradigm. Ecology, 74, 1659-1673.

Linacre, E. (1992) Climate data and resources: a reference and guide. Routledge, New York.

Lindenmayer, D.B. (1989) The ecology and habitat requirements of Leadbeater's Possum. PhD Thesis, Australian National University, Canberra.

Lindenmayer, D.B. (1991) A note on the occupancy of nest trees by Leadbeater's Possum in the montane ash forests of the Central Highlands of Victoria. Victorian Naturalist, 108, 128-129.

Lindenmayer, D.B. (1994) The impacts of timber harvesting on arboreal marsupials at different spatial scales and its implications for ecologically sustainable forest use and nature conservation. Sustainability in southern temperate forest ecosystems (eds T.W. Norton and S. Dovers), pp. 31-50. CSIRO, Melbourne, Australia.

Lindenmayer, D.B. (1996) Wildlife and woodchips: Leadbeater's Possum as a testcase of ecologically sustainable forestry. Australian Natural History Series. New South Wales University Press, Sydney, Australia.
Lindenmayer, D.B. \& Cunningham, R.B. (1996) Microscale forest classification for zoning wood production areas to conserve a rare species threatened by logging operations in south-eastern Australia. Environmental Monitoring and Assessment, 39, 543-557.

Lindenmayer, D.B. \& Lacy, R.C. (1995) Metapopulation viability of arboreal marsupials in fragmented old growth forests: a comparison among species. Ecological Applications, 5, 183-199.

Lindenmayer, D.B. \& Meggs, R.A. (1996) Use of den trees by Leadbeater's Possum (Gymnobelideus leadbeateri). Australian Journal of Zoology, 44, 625-638.

Lindenmayer, D.B. \& Nix, H.A. (1993) Ecological principles for the design of wildlife corridors. Conservation Biology, 7, 627-630.

Lindenmayer, D.B. \& Possingham, H.P. (1995a) The risk of extinction: ranking management options for Leadbeater's Possum. Centre for Resource and Environmental Studies, The Australian National University and The Australian Nature Conservation Agency, Canberra, Australia.

Lindenmayer, D.B. \& Possingham, H.P. (1995b) Modeling the impacts of wildfire on metapopulation behavior of the Australian arboreal marsupial, Leadbeater's Possum, Gymnobelideus leadbeateri. Forest Ecology and Management, 74, 197-222.

Lindenmayer, D.B. \& Possingham, H.P. (1996) Modeling the relationships between habitat connectivity, corridor design and wildlife conservation within intensively logged wood production forests of south-eastern Australia. Landscape Ecology, 11, 79-105.

Lindenmayer, D.B., Smith, A.P., Craig, S.A. \& Lumsden, L.F. (1989) A survey of the distribution of Leadbeater's Possum, Gymnobelideus leadbeateri McCoy in the Central Highlands of Victoria. Victorian Naturalist, 106, 174-178.

Lindenmayer, D.B., Cunningham, R.B., Tanton, M.T. \& Smith, A.P. (1990a) The conservation of arboreal marsupials in the montane ash forests of the Central Highlands of Victoria, south-east Australia. II. The loss of trees with hollows and its implications for the conservation of Leadbeater's Possum Gymnobelideus leadbeateri McCoy (Marsupialia: Petauridae). Biological Conservation, 54, 133-145.

Lindenmayer, D.B., Cunningham, R.B., Tanton, M.T. \& Smith, A.P. (1990b) The conservation of arboreal marsupials in the montane ash forests of the Central Highlands of Victoria, south-east Australia. I. Factors effecting the occupancy of trees with hollows. Biological Conservation, 54, 111-131.

Lindenmayer, D.B., Norton, T.W. \& Tanton, M.T. (1990c) Differences between the effects of wildfire and clearfelling in montane ash forests of Victoria and its implications for fauna dependent on tree hollows. Australian Forestry, 53, 61-68.

Lindenmayer, D.B., Nix, H.A., McMahon, J.P., Hutchinson, M.F. \& Tanton, M.T. (1991a) The conservation of Leadbeater's Possum Gymnobelideus leadbeateri (McCoy): a case study of the use of bioclimatic modeling. Journal of Biogeography, 18, 371-383.

Lindenmayer, D.B., Cunningham, R.B., Tanton, M.T., Nix, H.A. \& Smith, A.P. (1991b) The conservation of arboreal marsupials in the montane ash forests of the Central High-lands of Victoria, south-east Australia. III. The habitat 
requirements of Leadbeater's Possum, Gymnobelideus leadbeateri McCoy and models of the diversity and abundance of arboreal marsupials. Biological Conservation, 56, 295-315.

Lindenmayer, D.B., Cunningham, R.B., Nix, H.A., Tanton, M.T. \& Smith, A.P. (1991c) Predicting the abundance of hollowbearing trees in montane ash forests of south-eastern Australia. Australian Journal of Ecology, 16, 91-98.

Lindenmayer, D.B., Cunningham, R.B., Tanton, M.T., Smith, A.P. \& Nix, H.A. (1991d) Characteristics of hollow-bearing trees occupied by arboreal marsupials in the montane ash forests of the Central Highlands of Victoria, south-east Australia. Forest Ecology and Management, 40, 289-308.

Lindenmayer, D.B., Cunningham, R.B., Tanton, M.T. \& Nix, H.A. (1991e) Aspects of the use of den trees by arboreal and scansorial marsupials inhabiting montane ash forests in Victoria. Australian Journal of Zoology, 39, 57-65.

Lindenmayer, D.B., Cunningham, R.B. \& Donnelly, C.F. (1993a) The conservation of arboreal marsupials in the montane ash forests of the Central Highlands of Victoria, south-east Australia. IV. The distribution and abundance of arboreal marsupials in retained linear strips (wildlife corridors) in timber production forests. Biological Conservation, 66, 207-221.

Lindenmayer, D.B., Cunningham, R.B., Donnelly, C.F., Tanton, M.T. \& Nix, H.A. (1993b) The abundance and development of cavities in montane ash-type eucalypt trees in the montane forests of the Central Highlands of Victoria, south-eastern Australia. Forest Ecology and Management, 60, 77-104.

Lindenmayer, D.B., Lacy, R.C., Thomas, V.C. \& Clark, T.W. (1993c) Predictions of the impacts of changes in population size and of environmental variability on Leadbeater's Possum, Gymnobelideus leadbeateri McCoy (Marsupialia: Petauridae) using population viability analysis: an application of the computer program VORTEX. Wildlife Research, 20, 68-87.

Lindenmayer, D.B., Boyle, S., Burgman, M.A., McDonald, D. \& Tomkins, B. (1994a) The sugar and nitrogen content of the gums of Acacia spp. in the Mountain Ash and Alpine Ash forests of Central Victoria and its potential implications for exudivorous arboreal marsupials. Australian Journal of Ecology, 19, 169-177.

Lindenmayer, D.B., Cunningham, R.B. \& Donnelly, C.F. (1994b) The conservation of arboreal marsupials in the montane ash forests of the Central Highlands of Victoria, south-east Australia. VI. Tests of the performance of models of nest tree and habitat requirements of arboreal marsupials. Biological Conservation, 70, 143-147.

Lindenmayer, D.B., Tanton, M.T. \& Viggers, K.L. (1994c) A note on the fur-inhabiting ectoparasites of Leadbeater's Possum, Gymnobelideus leadbeateri McCoy (Marsupialia: Petauridae). Australian Mammalogy, 17, 109-111.

Lindenmayer, D.B., Ritman, K.R., Cunningham, R.B., Smith, J. \& Howarth, D. (1995) Predicting the spatial distribution of the Greater Glider, Petauroides volans Kerr in a timber production forest block in south-eastern Australia. Wildlife Research, 22, 445-456.

Lindenmayer, D.B., Mackey, B.G. \& Nix, H.A. (1996) Climatic analyses of the distribution of four commercially-important wood production eucalypt trees from south-eastern Australia. Australian Forestry, 59, 11-26.

Lindenmayer, D.B., Cunningham, R.B. \& Donnelly, C.F. (1997) The collapse of hollow trees in contiguous forest and wildlife corridors in the forests of Central Victoria, south eastern Australia. Ecological Applications, 7, 625-641.

Lindenmayer, D.B., Mackey, B.G., Mullins, I., McCarthy, M.A., Gill, A.M., Cunningham, R.B. \& Donnelly, C.F. (1999) Factors affecting stand structure in forests - are there climatic and topographic determinants ? Forest Ecology and Management, 123, 55-63.

Lowry, W.P. (1967) Weather and life. An introduction to biometeorology. Academic Press, New York.

Lugo, A.E. (1996) Ecosystem management requires good ecology. Caring for the forest: research in a changing world, pp. 13-21. IUFRO XX World Congress Report, Vol. II, 6-12 August 1995, Tampere, Finland.

Macfarlane, M.A. (1988) Mammal populations in Mountain Ash (Eucalyptus regnans) forests of various ages in the Central Highlands of Victoria. Australian Forestry, 51, 14-27.

Mackey, B.G. (1993) A spatial analysis of the environmental relations of rainforest structural types. Journal of Biogeography, 20, 303-336.

Mackey, B.G. (1994) Predicting the potential distribution of rainforest structural types. Journal of Vegetation Science, 5, 43-54.

Mackey, B.G. (1996) The role of GIS and environmental modeling in biodiversity conservation. Proceedings of the Third International Conference/Workshop on Integrating GIS and Environmental Modeling, Sante Fe, New Mexico. National Centre for Geographical Information Analysis. CD-ROM.

Mackey, B.G., Nix, H.A., Hutchinson, M.F., McMahon, J.P. \& Fleming, P.M. (1988) Assessing representativeness of places for conservation reservation and heritage listing. Environmental Management, 12, 501-514.

Mackey, B.G., Sims, R.A., Baldwin, K.A. \& Moore, I.D. (1996) Spatial analysis of boreal forest ecosystems: results from the Rinka Lake case study. GIS and environmental modeling: progress and research issues (eds M.F. Goodchild, B.O. Parks, C. Johnston, D. Maidment, M. Crane and S. Glendenning), pp. 187-190. GIS World Books, Fort Collins, USA.

Mackey, B.G., Mullen, I., Sims, R., Baldwin, K., Gallant, J. \& McKenney, D.W. (2000) Towards a spatial model of boreal forest ecosystems: the role of digital terrain analysis. Digital terrain analysis: principles and applications (eds J. Wilson and J. Gallant), pp. 391-422. John Wiley and Sons Inc., New York.

Margules, C.R. \& Stein, J.L. (1989) Patterns in the distributions of species and the selection of nature reserves: an example from the Eucalyptus forests in south-eastern New South Wales. Biological Conservation, 50, 219-238.

McCarthy, M.A. \& Lindenmayer, D.B. (2000) Spatially correlated extinction in a metapopulation model of Leadbeater's Possum. Biodiversity and Conservation, 9, 47-63.

McKenney, D.W., Mackey, B.G. \& Zavitz, B.L. (1999) Calibration and sensitivity analysis of a spatially-distributed solar radiation model. International Journal of Geographical Information Science, 13, 49-65. 
Meentemeyer, V. \& Box, E.O. (1987) Scale effects in landscape studies. Landscape heterogenity and disturbance (ed. M.G. Turner), pp. 15-34. Springer-Verlag, New York.

Miller, K.A. (1978) Energy at the surface of the earth. Academic Press, New York.

Milne, B.T., Turner, M.G., Wiens, J.A. \& Johnson, A.R. (1992) Interactions between the fractal geometry of Landscapes and Allometric Herbivory. Theoretical Population Biology, 41, 337-353.

Moore, I., Norton, T.W. \& Williams, J.E. (1993) Modeling environmental heterogenity in forested landscapes. Journal of Hydrology, 150, 717-747.

Mueck, S.G. (1990) The floristic composition of Mountain Ash and Alpine Ash forests in Victoria. SSP Technical Report No. 4. Department of Conservation and Environment, Victoria, Australia.

Mueck, S.G., Ough, K. \& Banks, J.C.G. (1996) How old are wet forest understories ? Australian Journal of Ecology, 21, 345-348.

Nix, H.A. (1986) A biogeographic analysis of the Australian elapid snakes. Atlas of elapid snakes. Australian flora and fauna series, Number 7 (ed. R. Longmore), pp. 4-15. Australian Government Publishing Service, Canberra, Australia.

Nix, H.A. \& Gillison, A.N. (1985) Towards an operational framework for habitat and wildlife management. Wildlife management in the forests and forestry-controlled lands in the tropics of the southern hemisphere (ed. J. Kikkawa), pp. 39-55. Queensland University Press, Brisbane, Australia.

Nix, H.A. \& Kalma, J.D. (1972) Climate as a dominant control in the biogeography of northern Australia and New Guinea. Bridge and barrier: the natural and control of Torres Strait Pages (ed. D. Walker), pp. 61-91. Australian National University Press, Canberra, Australia.

Nix, H.A. \& Switzer, M.A. (1991) Rainforest animals. Atlas of vertebrates endemic to Australia's wet tropics. Kowari, 1, $1-112$.

Nix, H.A., McMahon, J.P. \& Mackenzie, D. (1977) Potential areas of production and the future of Pigeon Pea and other grain legumes in Australia. The potential for Pigeon Pea in Australia Proceedings of the Pigeon Pea (Cajanus Cajan (L.) Millsp ) (eds E.S. Wallis and P.C. Whiteman). Department of Agriculture and University of Queensland, Brisbane, Australia.

Orlanski, I. (1975) A rational subdivision of scales for atmospheric processes. Bulletin of the American Meteorological Society, 56, 527-530.

Ostendorf, B. (1966) Modeling the influence of hydrological processes on spatial and temporal patterns of $\mathrm{CO}_{2}$ soil efflux from an arctic tundra catchment. Arctic and Alpine Research, 28, 318-327.

Ough, K. \& Ross, J. (1992) Floristics, fire and clearfelling in wet forests of the Central Highlands of Victoria. Silvicultural Systems Project Technical Report No. 11. Department of Conservation and Environment, Melbourne, Australia.

Pedley, L. (1986) Derivation and dispersal of Acacia (Leguminosae) with particular reference to Australia, and the reconstruction of Senegalia and Racosperma. Botanical Journal of the Linnaean Society, 92, 219-254.

Pedlosky, J. (1979) Geophysical fluid dynamics. SpringerVerlag, Berlin, Germany.
Pickett, S.T.A., Kolasa, J., Armesto, J.J. \& Collins, S.L. (1989) The ecological concept of disturbance and its expression at various hierarchical levels. Oikos, 54, 129-136.

Poff, N.L. (1997) Landscape filters and species traits: towards mechanistic understanding and prediction in stream ecology. Journal of the North American Benthic Society, 16, 391-409.

Prentice, I.C., Cramer, W., Harrison, S.P., Leemans, R., Monserud, R.A. \& Solomon, A.M. (1992) A global biome model based on plant physiology and dominance, soil properties and climate. Journal of Biogeography, 19, 117-134.

Price, D.T., Mckenney, D.W., Nalder, I.A., Hutchinson, M.F. \& Kesteven, J.L. (2000) A comparison of two statistical methods for spatial interpolation of Canadian monthly mean climate data. Agricultural and Forest Meteorology 101, 81-94.

Robinson, G.K. (1991) That BLUP is a good thing: the estimation of random effects. Statistical Science, 6, 15-32.

Rosenberg, N.J., Blad, B.L. \& Verma, S.B. (1983) Microclimate: the biology environment, 2nd edn. John Wiley and Sons, New York.

Roughgarden, J., Gaines, S.D. \& Pacala, S.W. (1987) Supply side ecology: the role of physical transport processes. Organisation of communities past and present (eds H. Gee and P.S. Giller), pp. 491-518. Blackwell Scientific Publications, Oxford, UK.

Saunders, D.A. \& Ingram, J. (1995) Birds of southwestern Australia. Surrey Beatty and Sons, Sydney, Australia.

Schneider, D.C. (1994) Quantitative ecology. Temporal and spatial scaling. Academic Press, San Diego, CA.

Sellers, P. (1991) Modeling and observing land-surface-atmosphere interactions on large scales. Surveys in Geophysics, 12, 85-114.

Short, H.L. (1984) Habitat Suitability Index models: the Arizona guild and layers of habitat models. US Fish and Wildlife Service. FWS/OBS-8210.70.

Smith, A.P. (1980) The diet and ecology of Leadbeater's Possum and the Sugar Glider. PhD Thesis, Monash University, Melbourne, Australia.

Smith, A.P. (1984a) Demographic consequences of reproduction, dispersal and social interaction in a population of Leadbeater's Possum (Gymnobelideus leadbeateri). Possums and gliders (eds A.P. Smith and I.D. Hume), pp. 359-373. Surrey Beatty and Sons, Sydney, Australia.

Smith, A.P. (1984b) Diet of Leadbeater's Possum Gymnobelideus leadbeateri (Marsupialia). Australian Wildlife Research, 11, 265-273.

Smith, A.P., Lindenmayer, D.B., Begg, R.J., Macfarlane, M.A., Seebeck, J.H. \& Suckling, G.C. (1989) Evaluation of the stagwatching technique for census of possums and gliders in tall open forest. Australian Wildlife Research, 16, 575-580.

Smith, A.P., Lindenmayer, D.B. \& Suckling, G.C. (1985) The ecology and management of Leadbeater's Possum. Research Report to World Wildlife Fund, University of New England, Armidale, NSW.

Smith, A.P., Nagy, K.A., Fleming, M.R. \& Green, B. (1982) Energy requirements and turnover in free-living Leadbeater's Possums, Gymnobelideus leadbeateri (Marsupialia: Petauridae). Australian Journal of Zoology, 30, 737-749.

Smith, J.D. \& Macfarlane, M.A. (1994) Modeling Leadbeater's Possum habitat in the Central Highlands of Victoria using GIS. Conference Proceedings: Resource Technology, New 
Opportunities Best Practice, pp. 393-403. Melbourne, Australia.

Smith, P.A. (1994) Autocorrelation in logistic regression modeling of species' distribution. Global Ecology and Biogeography Letters, 4, 47-61.

Specht, R. (1983) Foliage projective covers of overstorey and understorey strata of mature vegetation in Australia. Australian Journal of Ecology, 8, 433-439.

Specht, R. \& Morgan, D.G. (1983) The balance between the foliage projective covers of overstorey and understorey in Australian vegetation. Australian Journal of Ecology, 6, 193-202.

Stommel, H. (1963) The varieties of oceanographic experience. Science, 139, 572-576.

Strahler, A.N. (1957) Quantitative analysis of watershed geomorphology. Transactions of American Geophysical Union, 38, 913-920.

Su, W. \& Mackey, B.G. (1997) A spatially explicit and temporally dynamic simulation model of forested landscape ecosystems. MODSIM 97: Proceedings of the International Congress on Modelling and Simulation, Hobart, Tasmania, 8-11 December 1997, Vol. 4 (eds A.D. McDonald and M. McAleer), pp. 1536-1640. The Modelling and Simulation Society of Australia Inc., Australia.

Swanson, F.J., Kratz, T.J., Caine, N. \& Woodmansee, R.G. (1988) Landform effects on ecosystem patterns and processes. Bioscience, 38, 92-98.

Taiz, L. \& Zeiger, E. (1991) Plant physiology. The Benjamin/ Cummings Publishing Co., Inc, Redwood City, CA.

Troll, C. (1972) Geoecology of the high-mountain regions of Euasia. Proceedings of the Symposium of the International Geographical Union Commission on High-Altitude Geoecology, 20-22 November 1969 (ed. C. Troll), pp. 1-13. MainzPranz Steiner Verlag GMBH, Wiesbaden, Germany.

Turner, M.G., Dale, V.H. \& Gardner, R.H. (1989) Predicting across scales: theory development and testing. Landscape Ecology, 3, 245-252.

Urban, D.A., O’Neill, R.V. \& Shugart, H.H. (1987) Landscape ecology. Bioscience, 37, 119-127.

USGS (2001) (http://www.gap.uidaho.edu/Van Horne, B. (1983) Density as a misleading indicator of habitat quality. Journal of Wildife Management, 47, 893-901.

Van Horne, B. \& Wiens, J.A. (1991) Forest bird habitat suitability models and the development of general habitat models. Fisheries and Wildlife Research Report No. 8, pp. 1-31. US Fish and Wildlife Service, Washington, DC.

Walker, J., Thompson, C.H., Fergus, I.F. \& Tunstall, B.R. (1981) Plant succession and soil development in coastal sand dunes of sub-tropical eastern Australia. Forest succession: concepts and applications (eds D.C. West, H.H. Shugart and D.B. Botkin), pp. 107-131. Springer-Verlag, New York.

Walker, J., Sharpe, P.J., Penridge, L.K. \& Wu Hsin, I. (1986) Competitive interactions between individuals of different size: the concept of ecological fields. Technical Memorandum $86 / 11$. CSIRO Institute of Biological Resources, Division of Water and Land Resources, Canberra, Australia.

Webb, L.J. (1968) Environmental relations of the structural types of Australian rainforest vegetation. Ecology, 49, 296-311.

Welsh, A., Cunningham, R.B. \& Lindenmayer, D.B. (1996) Methods for analyzing data with extra zeros: ZIP regression models with applications for surveys of rare species. Ecological Modeling, 88, 297-308.

Wiens, J.A. (1989) Spatial scaling in ecology. Functional Ecology, 3, 385-397.

Wiens, J.A., Schooley, R.L. \& Weekes, R.D. (1997) Patchy landscapes and animal movements: do beetles percolate? Oikos, 78, 257-262.

Wiens, J.A., Stenseth, N.C., Van Horne, B. \& Ims, R.A. (1993) Ecological mechanisms and landscape ecology. OIKOS, 66, 369-380.

Williams, J. \& Gill, A.M. (1995) The impact of fire resources on native forests in eastern New South Wales. Environmental Heritage Monograph Series, 2, 1-68.

Wilson, J.P. (1996) Environmental applications of digital terrain analysis. GIS World Books.

Wilson, J.P. \& Gallant, J.C. (1996) EROS: a grid-based program for estimating spatially distributed erosion indices. Computers and Geosciences, 22, 707-712.

Wilson, J.P. \& Gallant, J.C. (2000) Digital terrain analysis: principles and applications. John Wiley and Sons Inc., New York.

Woodgate, P.W., Peel, W.D., Ritman, K.T., Coram, J.E., Brady, A., Rule, A.J. \& Banks, J.C. (1994) A study of the old-growth forests of East Gippsland. Department of Conservation and Natural Resources, Victoria, Australia.

Woodward, F.L. \& Williams, B.G. (1987) Climate and plant distribution at global and local scales. Vegetatio, 69, 189-197.

\section{BIOSKETCHES}

Brendan Mackey is a Reader in Ecology and Environmental Science at The Australian National University. Previously, he has worked as a researcher with The Australian CSIRO and The Canadian Forest Service. Dr Mackey currently leads a project on 'Ecosystem vulnerability to Change' within the Cooperative Research Centre for Greenhouse Accounting. Dr Mackey is an Associate Editor for Environmental Conservation, and is a lead author of a new book entitled: Wildife, fire and future Climate: a forest ecosystem perspective (CSIRO Publishing).

David Lindenmayer is a Senior Fellow at the Centre for Resource and Environmental Studies at The Australian National University. He is the author of six books and more than 250 scientific articles on such diverse topics as forest ecology and management, wildlife biology (particularly on mammals and birds), conservation biology and landscape ecology. Dr Lindenmayer has had a long-term interest in the ecology of montane forests and has maintained an 18-year research program in the Mountain Ash forests of the Central Highlands of Victoria. 